\title{
Changes in Dairy Products Value Chain in Georgia
}

\author{
Rami Al Sidawi ${ }^{1, *}$, Teo Urushadze ${ }^{2}$ and Angelika Ploeger ${ }^{1}$ \\ 1 Specialized Partnerships in Sustainable Food Systems and Food Sovereignty, Faculty of Organic Agricultural \\ Sciences, University of Kassel, 37213 Witzenhausen, Germany; a.ploeger@uni-kassel.de \\ 2 School of Agricultural and Natural Sciences, Agricultural University of Georgia, 0159 Tbilisi, Georgia; \\ t.urushadze@agruni.edu.ge \\ * Correspondence: rami.alsidawi@uni-kassel.de; Tel.: +49-055-42981621
}

Received: 19 June 2020; Accepted: 15 July 2020; Published: 22 July 2020

check for updates

\begin{abstract}
The livestock sector, as a part of the traditional food system in Georgia, occupies a considerable portion of the national economy. Though smallholder farmers are the key suppliers at the primary stage in the food value chain, the empowerment of smallholder farmers in the dairy production system in Georgia is a questionable matter. This research study reports the results of changes in the dairy sector in Georgia (Caucasus) after becoming independent from the Soviet Union (literature survey) and how these changes are seen by experts in the dairy value chain. In addition, this study aimed to look in-depth at the dynamics of the value chain of dairy in Georgia and examine the current dairy production policies. Qualitative research was applied as the methodology for expert interviews in 2019. The findings showed the difficulties experienced by the local and national dairy market sectors in Georgia nowadays. Where these difficulties were analyzed by the parameters of the value chain, it states the impact of the current regulations and policies on the safety and the quality of dairy production in the country and the depth of social, economic, and ethical impacts on the marketing of dairy products for smallholders. Furthermore, the Sustainable Development Goals on the dairy value chain are described.
\end{abstract}

Keywords: dairy products; value chain; Georgia; food safety; expert interviews; small farmers

\section{Introduction}

After the collapse of the Soviet Union, a difficult political, socio-economic situation arose in Georgia, which was further aggravated by the civil war in the country. The government saw the formation of self-sufficient farms as one of the ways to get out of the challenging economic situation, and in 1992 the land reform began, which involved the transfer of land to the Georgian population. As a result, thousands of small farms (on average, about 1 hectare of land) have been established in the Georgian regions [1-4]. Though the agricultural sector in Georgia has been decreasing since the collapse of the Soviet Union, it turned out to be much more reliant on smallholders' farmers, which now deliver about $90 \%$ of the entire agricultural products being produced in Georgia [5]. Nevertheless, Georgia is still dependent on imports in general, and the dairy products sector has high imports.

In the last few years, due to the fact of this reform, which mainly aimed to solve the social issues, the Georgian economy has been under transformation [6]. This changing period can be alienated in two core stages: from 1990 to 2003 and 2004 up to present. After 2004, economic strategies started to integrate the concepts of economic liberalization and modernization [7]. However, $90 \%$ of the smallholder farmers who live in the rural areas are dependent mainly on grass-based dairy production, and they are using the available pasture in the summertime and reliant on hay in the winter period. After the collapse of the Soviet Union in 1991, the privatization of pasture lands was halted [8], and in 2008, the state-owned large areas of land designated for rangelands were passed to the municipalities 
to decide how and by whom to be used. Often the mountain pastures are used informally for free and without any restrictions by local herders or nomads [9].

Milking cows and producing a good quality of milk helped the country economically with the development of the dairy sector, as well as the other livestock like sheep or goats [10]. According to IFAD [11], there is nearly one million head of livestock in Georgia, around 50\% of which are dairy cows. Nevertheless, between 2004 and 2014, there was a reduction of dairy cow number by $25 \%$, and that was faced with a $40 \%$ increase in milk production per cow, which is due to the change in the cow's breeds and feeding system. However, between 2006 to 2015, the milk production increased by $11 \%$ which is still lower than the political scope [11].

The cheese industry was one of the most important industrial revolutions in Georgia. It is worth noting that, under the Soviet system between 1921 and 1991, the goal of economic decision-makers at that time relied on the quantity in the manufactured cheese. That helped to feed the people of the USSR [12]; the reason was to manufacture only four types of Georgian cheese that are easy and fast to produce: Imeruli, Sulguni, Karkhunli, and Guda [12-14]. After the collapse of the Soviet Union and the proclamation of independence, Georgia strongly witnessed the return of national identity which was, for example, the revival of culinary traditions. Many of which were lost due to the industrialization of agriculture in the Soviet era, although Georgia is home to dozens of other cheeses [15].

In the last few years, the cheese market has been formalized in Georgia, as smallholder farmers provided the means, projects, and necessity to grow, they developed the sector of small and medium dairy projects and secured an increasingly formal market $[5,10,16]$. According to CARD [17] in 2016 and because of the high demands on traditional cheese sorts, the consumption of cheese was $12.7 \mathrm{~kg}$ per capita, followed by milk consumption of 8.3 litres per capita. Today, cheese is the most daily food consumed among dairy products in Georgia, and this consumption is progressively increasing [17].

Despite the continuous development of the cheese sector, there are restrictions currently facing this development. There are farmers in rural areas who decide to make cheese at home and selling it informally. So, this product is completely free of food safety control and might be produced under low hygiene standards. Since the National Food Agency (NFA) is not able to monitor this production at smallholder farmers' homes, a law was implemented in 2020, prohibiting the sale of home-made cheese; therefore, it is only valid for family consumption $[6,10,11,17]$.

Likewise, one of the current problems facing the development of this sector is the inability to monitor and control unregistered companies and which might be incompatible with the existing regulations, and prevents access to fair competition and thus destabilizes the sector completely $[6,10,17,18]$. One of the biggest problems is the use of powdered milk in the cheese industry, thus creating an imbalance in the local markets and increasing the exports of powdered milk, which undermines the potential added value of Georgian dairy products. In 2017, NFA made changes to the regulation on milk and dairy products, which prohibits using the name "cheese" on the products containing milk powder [10,17-19].

Thus, and based on the foregoing, the purpose and importance of the study lies in the scrutiny and study of the current dairy production policies in Georgia and the current and future difficulties they face, especially in the post-Soviet period, and any attempt to define the relationship between stakeholders and small farmers.

\section{Dairy Food Chain}

The supply chain is a multiform collaborative activity designed to create "value" through a combined effort within the chain. This activity includes aspects such as processing, packaging, transport, storage, and retailing [20]. All these activities and actors will take the product from its conception to disposal.

A value food chain starts along a supply chain. A value food chain is a set of businesses and their interactions that bring farm products from its conception and design to its end use by the consumer and even further on to waste management. Producers and consumers of agricultural goods form 
strategic alliances with other supply chain players such as aggregators, processors, distributors, and retailers to improve financial returns through product variation that promote social or environmental values $[17,21]$.

The activities allow adding "value: to it during the passage of the product through the chain. Even today, considering ecological or social factors in agriculture and food business, economic factors mostly describe this value. As a result, it is possible to describe the value chain with what and where the values are added in the supply chain for and by these activities and players [22,23]. Therefore, each factor in the chain (Figure 1) is utilized to ensure that the value of the product resulting from this chain is high and meets the satisfaction of the consumer [24].

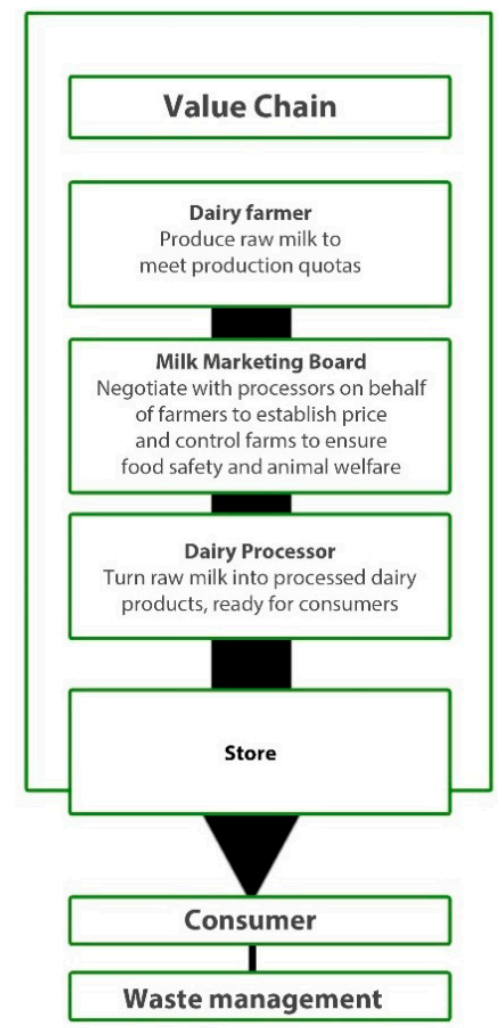

Figure 1. A shortened illustration of the dairy value chain [25].

The food value chain facing rapid changes in developing countries, many factors lead to this change, as population increases, income growth, and local and global expansion in the food trade change, distribution, and sale operations. For example, the consumer and the government are demanding not only a product with proper specifications and a low price but unique characteristics that exceed the price, such as food safety certification, nutritional content, low greenhouse gas emissions, and many others [21].

Georgia, as a developing country in a transitional economy [26] and the food value chains, are affected by these institutional changes, too [27]. International forces, regional and global quality standards, are influencing the Georgian dairy chain as well. Therefore, the economic aspect is essential in understanding the value chain, as it provides a solid ground. According to FAO [28], Georgia, a country with comprehensive free trade, is open for imports of dairy products from the European Union (EU). Still, it cannot export its dairy products to the EU due to food safety and milk quality issues [29]. Besides, Georgia possesses an essential heritage (traditional) of dairy products. Still, these products do not have great market visibility, as the economic factors of the chain did not give a particular concern to heritage at the moment [29]. However, if the local food chain performance will be provided with a critical analysis focusing and comparing with the global ones, it may help to accurately evaluate the real benefits and problems of local and global food chains [30]. 
Therefore, there are many indicators by which value chains can be developed, compared, and distinguished. For example, local milk could be easily compared to imported milk. This difference in performance can be explained partly by important factors in the chain. That affects the degree of the evaluation of many indicators. For example, the strategy of animal feeding and the choice of animal feed varies depending on the system followed or it may rely on old traditions (cultural heritage). Also, the rotation of crop possibilities and their productivity per hectare per cow, animal welfare, low or high greenhouse gas emissions, as well as the quality of fats in the milk [17,30,31] can be possible indicators. These lead to the existence of different products, which generates different marketing strategies, which in turn lead to the arrangement of a diverse supply chain. Besides, all of this affects the relationships between all actors in the supply chain, the difference in prices, and transparency for consumers.

On the contrary, some of the global strategies being used in standardizing products, reduce the transparency component for both consumers and farmers. Still, they may help, on the other hand, to reduce production costs and reduce waste [30,31]. However, all actors in the dairy food chain are linked by the product flow (supply chain) and the economics being involved. For consumers besides food safety and food quality, additional factors are essential for dairy consumption, such as social and environmental factors, as well as traditional or on-farm produced foods $[17,21,30]$. Therefore, constructive support for local products and considering the economic, ethical, and social aspects, cultural heritage, and traditions may help to develop a "consumer-driven" value chain and, which in turn, directly and indirectly, affect sustainability and access to food of high quality and safety standards [22,30].

This research paper is providing comprehensive literature that could help to define an appropriate value chain for dairy products from the "stakeholders" point of view, especially driven by consumers' expectations.

Moreover, the study aims to (i) investigate the dynamics of the dairy food value chain by examining the relationship between the stakeholders as the result of a literature review; (ii) scrutinize the current dairy production policies such as safety regulations to define the difficulties that are facing the local and national dairy market sectors in Georgia; (iii) explore the impact of the socio-economic on the smallholder dairy farmers when marketing their products focusing on the region of Kvemo Kartli in Georgia, and (iiii) investigating the best mechanisms to be implemented to empower better management in the dairy value chain of smallholder dairy farmers in this region and Georgia in general.

These documents provide a valuable tool for illustrating the complexity of the chain. It also helps to understand the experts' point of view and how to see a development in the dairy chain linked with political, economic and ecological as well as social situations of farmers in this region of Georgia Figure 2 demonstrates the hypothesis presented in this work. On the other hand, the expert interviews help in evaluating relationships between actors along the vertical and horizontal dimensions of the dairy value chain and understanding the contribution of the factors to this chain, such as ethnic and socio-economic dynamics, which were highlighted. It also helps to understand the relationships among the various interest groups, such as investors, processors, big companies, producers, etc. 


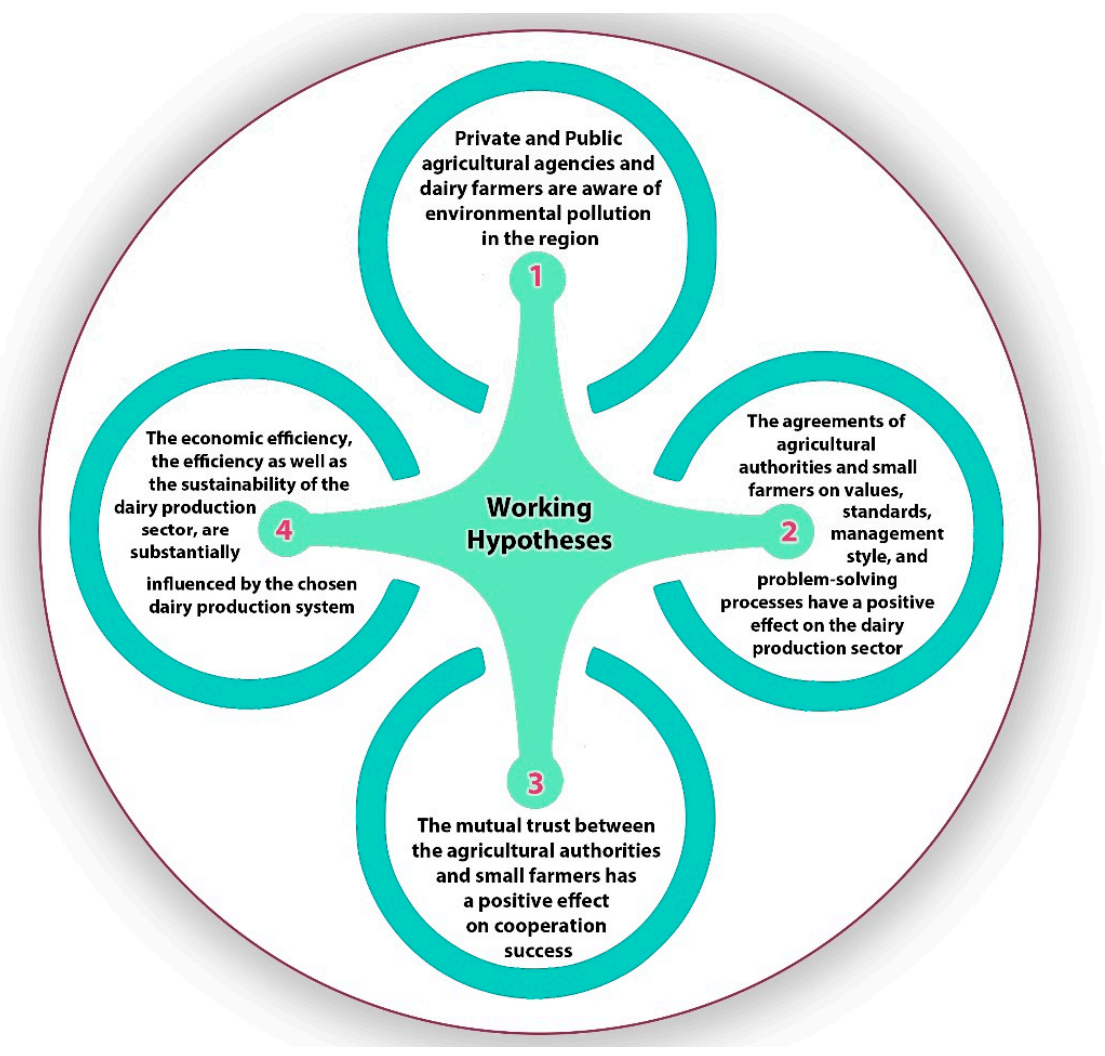

Figure 2. Working hypotheses.

\section{Materials and Methods}

This research study is part of a cooperative research work between the University of Kassel, Faculty for Organic Agricultural Sciences and the Agricultural University of Georgia since 2018.

The work was divided into two parts, first providing a review of the current state of the value chain analysis as a tool to evaluate the Georgian dairy sector, second, conducting expert interviews.

\subsection{Region}

The study area, Kvemo Kartli (Figure 3), is situated in the south part of Eastern Georgia. Kvemo Kartli fills $9.4 \%$ of the whole territory of Georgia which is 6.5 thousand square Kilometers [32].

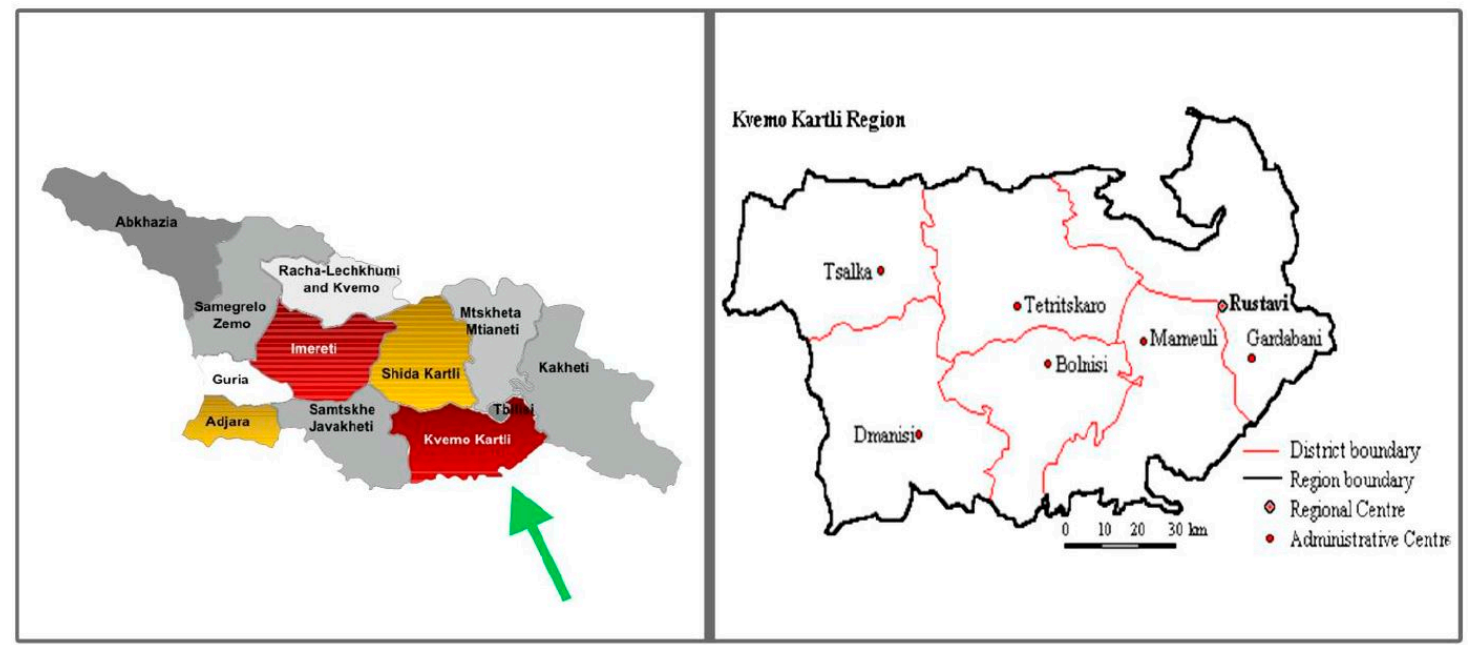

Figure 3. Kvemo Kartli region, source: [33]. 
The Kvemo Kartli region, which is close to the capital Tbilisi, Georgia, is considered the biggest beef producer, and families earn their living from livestock, cattle, and sheep. Usually, they own an average of five cattle, and up to 40 sheep. However, the production of good quality of locally produced meat and dairy products is a growing market in Georgia.

Farmers in Kvemo Kartli face difficulties related to the lack of modern farming machinery, lack access to vets, and poor knowledge of and connection to the meat and dairy international markets [34].

\subsection{A Review of the Current State of the Value Chain}

This paper was designed to provide a review of the current state of the value chain analysis as a tool to evaluate the Georgian dairy sector. Besides, a literature review and gathering primary data through expert interviews were used to obtain insights into the Georgian dairy value chain.

To clarify the factors of the comprehensive literature research, we conducted an online search using keywords such as "value chain," "dairy Georgia," milk production Georgia", and "food safety Georgia." Authorized documents, together with regulation guidelines, government policy regulations, and reports published by the Georgian government agencies and their research institutes, as well as documents from international organizations, have been evaluated as reliable sources (see Appendix A. Literature Review Keywords).

A total of 35 interviewees were selected. Due to the sensitivity of the information investigated in this research, some of the experts refused to meet us and expressed their inability to disclose that information, besides their limited time. Twenty-two dairy chain experts took part in the survey.

The value chain of the dairy is usually affected by the different variables such as the independent variable (such as age, gender, and education), the intervening variable (government policies), and the moderating variable (e.g., extension services) [34]. In this study, the expert interviewees were chosen based on the intervening variables and different moderating variables such as the rearing system adopted by the farmers living in the Kvemo Kartli region. Figure 4 shows the main criteria of the selection for the expert interviewees.

\section{Concept Framework}

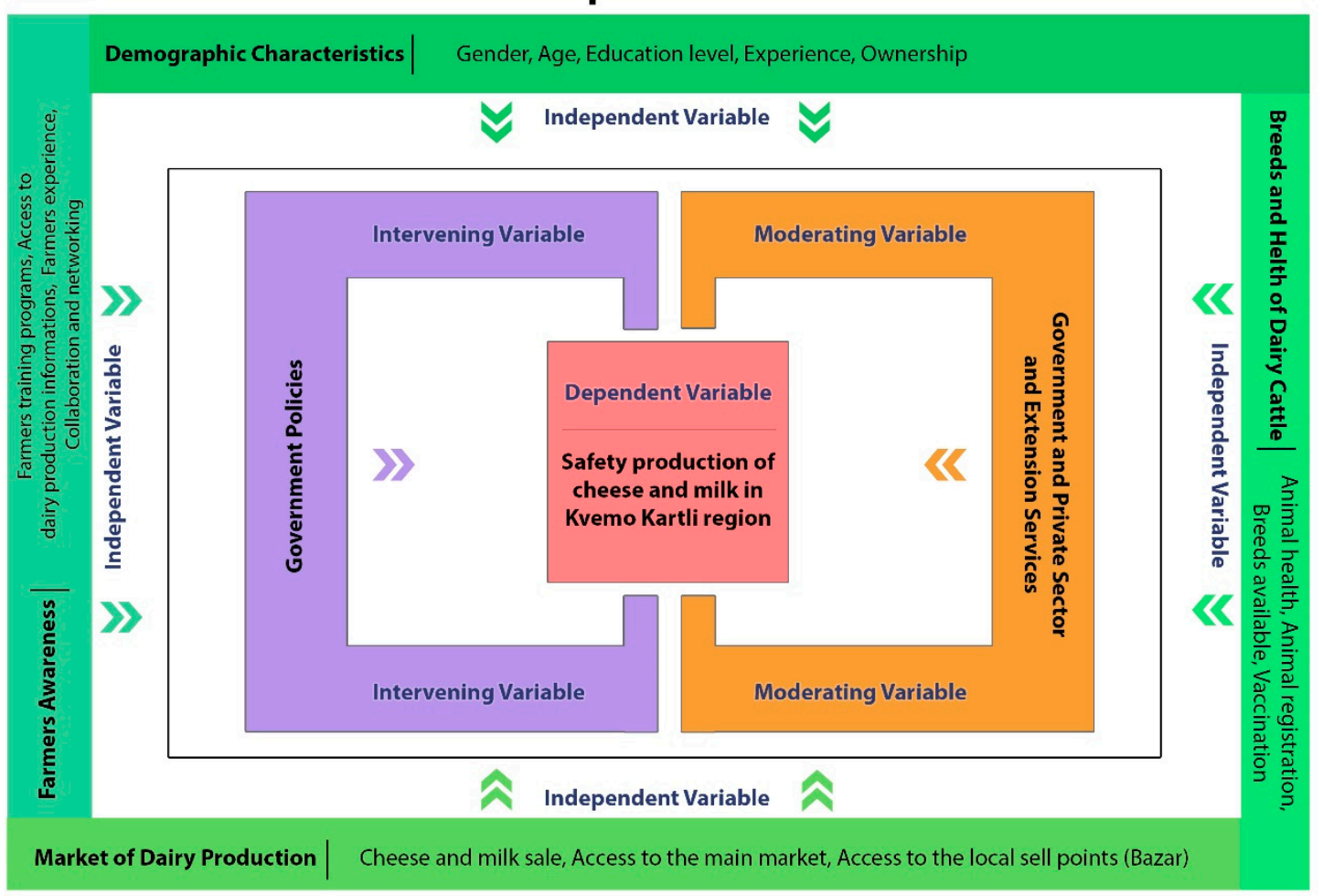

Figure 4. The main criteria of the selection for the expert interviewees. 
Usually, the independent variable influences the value of the dependent variable, as there is a cause-effect relationship between these two variables. Thus, the variable that affects the cause and effect relationship between these two variables is the moderator variable [35]. The moderating variable will explain one of the research aspects, which will be for this research the cultural issues affecting the dairy products, for example, which rearing system is adopted by the farmers living in the Kvemo Kartli region. One of the main characteristics of choosing the interviewees is the intervening variable, as an intervening variable is a variable that may affect the cause and effect relationship of dependent and independent variables, but it may be difficult to measure it clearly or be ignored during research [35], which is in our study represented by the government policies. For this, we executed an analysis of interviews that were done in a different government facility.

\section{Data Collection}

Data collection for this work occurred in June 2019. The research was based on empirical data, which consisted of a semi-structured personal face-to-face interview $(N=22)$, which can help to illuminate several problems that may not appear with other qualitative research methods [36].

The guided interviews were taken with representatives of the dairy industry, governmental bodies', and people working in quality laboratories of private sectors and international organizations. According to Mayring [37], the structured content analysis was used for the evaluation with regards to the quality criteria (objectivity, reliability, validity). Because of the different interests among the participants being interviewed, we prepared an interview guide, which helped to ensure that the data collection was similar and systematic (in concentrating on the relevant topics).

In total (Table 1), six experts from the dairy industry (DI), 12 experts from the governmental body's and laboratory $(\mathrm{G})$, three experts from the private sector $(\mathrm{P})$, and one expert from FAO (IO) were interviewed $(N=22)$. These interviewees were chosen carefully to represent the target groups. All interviews were conducted in both languages Georgian and/or English. A translator was required.

Table 1. Codes and Interview Details.

\begin{tabular}{|c|c|c|}
\hline Code & Position & Interview Date \\
\hline Government/G1 & Chief Director & 10.06.2019 \\
\hline Government/G2 & Director & 12.06 .2019 \\
\hline Government/G3 & Director & 12.06 .2019 \\
\hline Government/G4 & Director & 12.06 .2019 \\
\hline Government/G5 & Director & 12.06 .2019 \\
\hline Government/G6 & Director & 12.06.2019 \\
\hline Government/G7 & Director & 12.06 .2019 \\
\hline Government/G8 & Director & 12.06 .2019 \\
\hline Government/G9 & Head of the department & 13.06.2019 \\
\hline Government/G10 & Chief Veterinarian & 13.06.2019 \\
\hline Government/G11 & Technical Veterinarian & 13.06.2019 \\
\hline Government/G12 & Technical Veterinarian & 13.06 .2019 \\
\hline Private sector/P1 & Food Safety Manager & 06.06 .2019 \\
\hline Private sector/P2 & Quality Manager & \\
\hline Private sector/P3 & Consultant & 07.06 .2019 \\
\hline Dairy industry/DI1 & Main Office-Team-Coordinator & 14.06 .2019 \\
\hline Dairy industry/DI2 & Senior Team Officer & 14.06 .2019 \\
\hline Dairy industry/DI3 & "The Queen of Cheese" & 09.06.2019 \\
\hline Dairy industry/DI4 & Technical Director & 11.06.2019 \\
\hline Dairy industry/DI5 & Georgian Farmers Association & 16.06 .2019 \\
\hline Dairy industry/DI6 & Certification Specialist & 16.06 .2019 \\
\hline International organization/IO1 & National Team Leader & 13.06.2019 \\
\hline
\end{tabular}


All participants were chosen through the personal contacts of the researchers. Moreover, according to Edwards et al. [38], the researcher must provide additional care in the validity of the interview material in the context of the qualitative research, and the interviewer can focus on the interview and build an understanding instead of being unfocused with extensive note-taking. For this reason, the interviews were recorded, after obtaining the permission of the interviewer first.

Yet, the sample size of this study seems to be small to conduct a decent research interview, it is enough to determine the required number of experts and choosing the right informants [39], but it does not allow the generalization of the results for the whole of Georgia. Thus, the results of this study may indicate tendencies for the dairy production situation and the current applied regulations in Georgia due to their qualitative nature. This investigation was made to gain primary expertise about the dairy value chain in Georgia because, in the next part of the empirical studies, dairy farmers of the region will be interviewed to catch their perspective.

The recorded audio files were transcribed using the MAXQDA 18 program. The interview guideline served as the basis for the main categories to be defined at the beginning. This approach is referred to as "deductive category formation" [37]. For the most accurate classification of the data, additional subcategories were added during the coding phase; this is called inductive category formation. Significantly, it is important to use coding, as text data are dense data, and its understanding and analysis take a long time. Therefore, through coding, this data can be indexed and formatted. Then we can get an overview of the data, understand it, and understand its relevance to research questions [40]. Table 2 shows all codes and sub-codes being used.

According to Eriksson et al. [41] and Cassell et al. [42], the ethical guidelines in this research have been taken into consideration, which states that every researcher should treat all study participants with respect. This was done, as mentioned previously, by informing all the interviewees about the research goal (development of the Georgian dairy value chain) and ensuring that their names were not mentioned if this was their desire.

All participants voluntarily joined in this research, and the permission to record the interviews have been asked each time before the meeting. Besides, all people interviewed for this research are undeniable.

Sufficient time has been given for interviews and in-depth engagement with participants. After completing the interviews and conducting data analysis, some participants were contacted and were given a complete transcript of their coded interviews to set whether the codes harmonized their standpoint.

According to Rädiker et al. [43], in this workflow, the data were first encoded by one person, and to demonstrate reliability, the coding was performed and checked by another person. To check the "interrater-reliability" to this work and to quantifies the quality of the qualitative analysis in a number and translates the work into a comprehensible with a familiar form, a coefficient like Kappa was calculated (Kappa $=0.89$ ) [44]. Based on Rädiker et al. [43], if the Kappa-value was $>0.81$, this means that we are talking about a very good result ("almost perfect"). This shows that the coding list was reliable. Discord points were then discussed; then, all the new changes in the coding groups were applied to all transcripts. 
Table 2. Codes and Sub-Codes.

\begin{tabular}{|c|c|c|c|c|c|c|c|c|}
\hline \multicolumn{9}{|c|}{ Codes } \\
\hline & Marketing & $\begin{array}{l}\text { Animal } \\
\text { Welfare }\end{array}$ & Import/Export & Investment & $\begin{array}{l}\text { Dairy Food } \\
\text { Regulation }\end{array}$ & $\begin{array}{l}\text { Government } \\
\text { Support }\end{array}$ & $\begin{array}{l}\text { Food Quality } \\
\text { and Safety }\end{array}$ & $\begin{array}{l}\text { Production } \\
\text { System }\end{array}$ \\
\hline \multirow{6}{*}{ Sub-codes } & Local market & $\begin{array}{l}\text { Animal } \\
\text { health }\end{array}$ & $\begin{array}{l}\text { Quality control } \\
\text { over the imported } \\
\text { dairy products }\end{array}$ & $\begin{array}{l}\text { private } \\
\text { sector }\end{array}$ & $\begin{array}{l}\text { Organic dairy } \\
\text { production }\end{array}$ & Farmer education & Heavy metals & $\begin{array}{c}\text { Production } \\
\text { development }\end{array}$ \\
\hline & Bazar & & Price difference & $\begin{array}{l}\text { Farmers } \\
\text { ownership }\end{array}$ & $\begin{array}{l}2020 \text { new } \\
\text { regulations }\end{array}$ & Farmer knowledge & Hygiene & $\begin{array}{l}\text { Milk collection } \\
\text { point }\end{array}$ \\
\hline & Main market & & & & $\begin{array}{l}\text { integration of } \\
\text { EU Regulation }\end{array}$ & $\begin{array}{l}\text { Control on the dairy } \\
\text { production value } \\
\text { chain }\end{array}$ & $\begin{array}{c}\text { Quality } \\
\text { parameters }\end{array}$ & Cheese varieties \\
\hline & Self-consumption & & & & & Veterinarian & Quality control & Milk powder \\
\hline & Dairy products coast & & & & & $\begin{array}{l}\text { International } \\
\text { organizations }\end{array}$ & & Challenges \\
\hline & $\begin{array}{l}\text { Dairy production in } \\
\text { Georgia (percentage) }\end{array}$ & & & & & $\begin{array}{l}\text { Government } \\
\text { cooperation }\end{array}$ & & Gender \\
\hline
\end{tabular}




\section{Results}

In this section, the results gathered from the literature study and expert interviews are presented and discussed. The literature study opens the view of how diverse and complex a dairy value chain is seen in different countries and from the different stakeholders in the dairy sector. Because the consumers decide which quality and expectation towards the dairy product they want to pay for, the different criteria of a dairy value chain are described in this part.

Furthermore, the opinions of these experts will be discussed on how the various factors that will be mentioned affect the value chain in Georgia.

\subsection{Stat of the Dairy Value Chain}

\subsubsection{Dairy Value Chain Based on Economics}

Economically, the value chain is of great importance, but its importance has increased, as it has become a tool for analyzing the country's economic relations in recent years. Georgia has suffered from significant economic difficulties since the collapse of the Soviet Union. It has persevered in developing this economy day after day, as analysis of the value chain was considered an important contribution to the interpretation of unequal development and continuous underdevelopment $[45,46]$.

The balance between growth on the one hand and collateral damage on the other hand and assistance in developing economic and political recommendations gave the economic value chain a leading role in developing the Georgian economy $[45,46]$.

This helped in the consistency of information within the value chain which is linked to the relations between small- and medium-sized companies and their allocation of profits and helped to establish a strong relationship between the public and private sectors which in turn helped to support the dairy sector and open new horizons in their economic growth

According to the Geostat Report, in 2017, half of the cows in Georgia, which are approximately 900,000 head of cattle, are milking cows, and the report has cleared that the productivity of cows has increased, but in return, the number of these cows has decreased (Figure 5). With a cow's productivity of about 1400 litres per year, Georgian milk production is still much lower than the European Union and other developed countries [47].

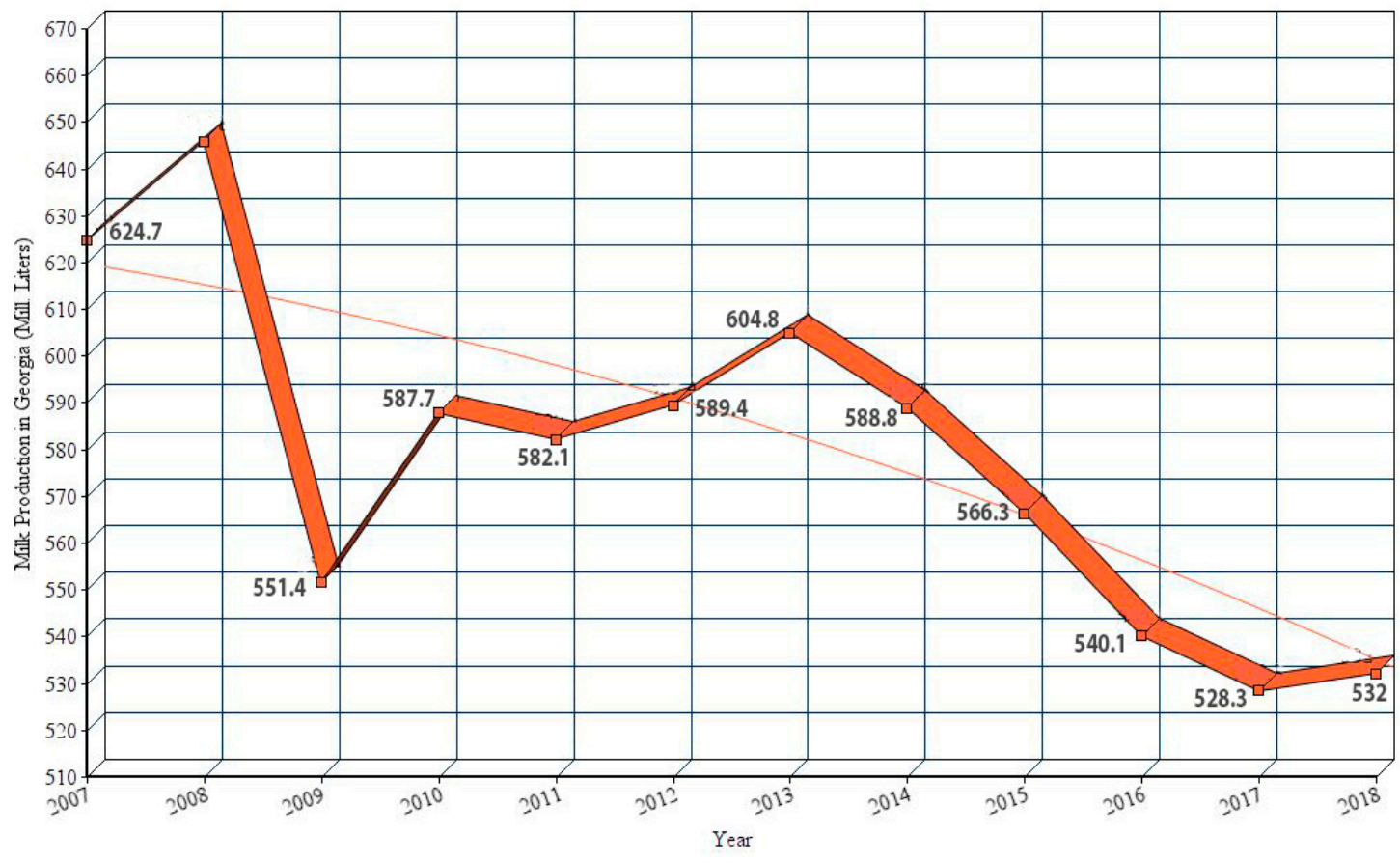

Figure 5. Annual milk production in Georgia (millions of litres) [47]. 
Based on Geostat Report in 2020 (Figure 6), in the first quarter of 2020, there was an increase in milk production by 5.0 per cent compared to the same period of the last year, and by 14 per cent compared to 2014, where production has become nearly 107.0 million litres [48].

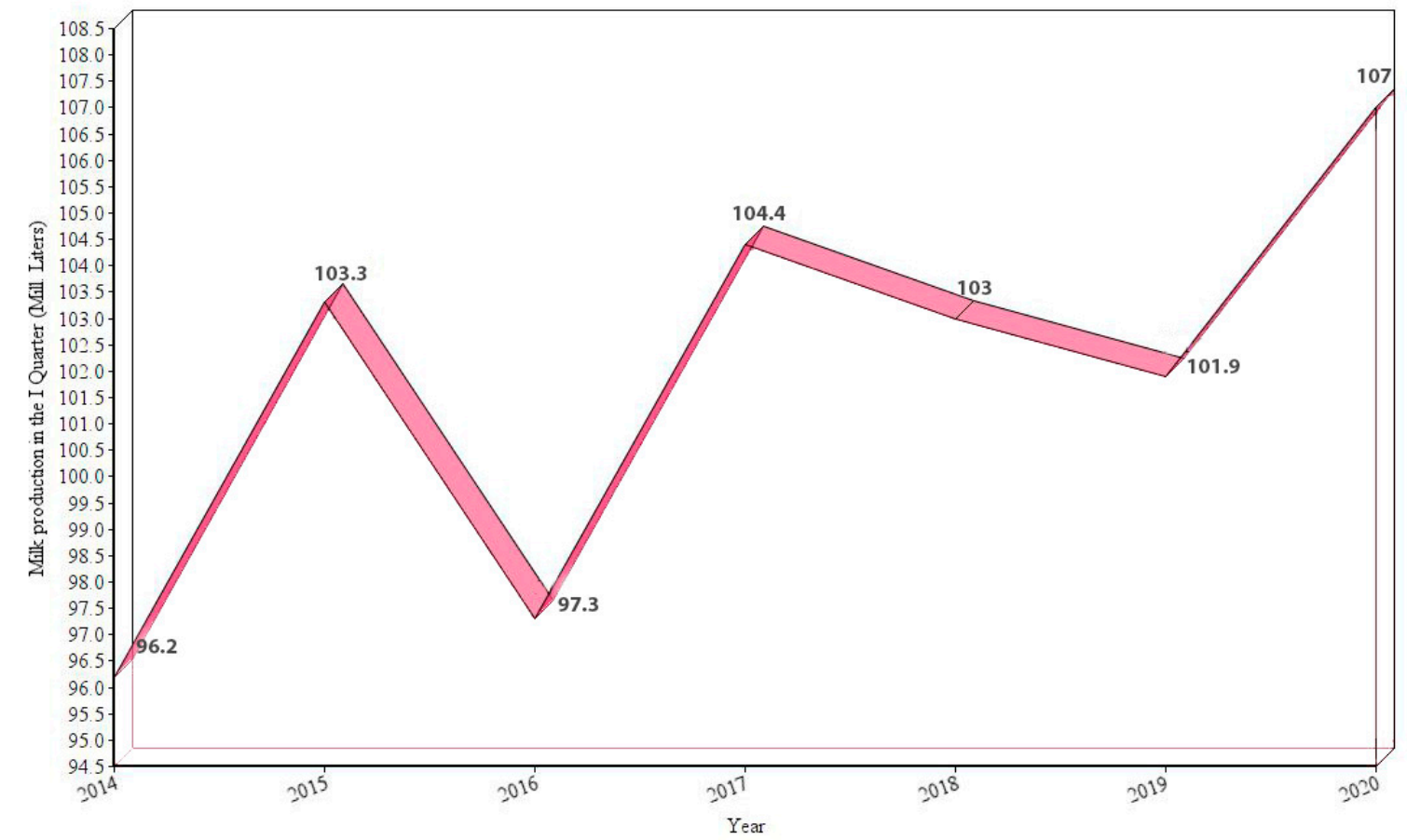

Figure 6. Milk production in the first quarter (January, February, and March) of 2014-2020 (millions of litres) [48].

\subsubsection{Dairy Value Chain Based on Ethics}

The dairy value chain also means consideration of animal welfare. These days the consumer's awareness about the quality and the safety of food is increasing; besides the concerns over food scares, such as salmonella or avian influenza, ethical factors are playing a major role in consumers' behaviour which cause farmers to consider the welfare of their animals [49].

Based on Mayfield et al. [49], almost all consumers in Great Britain, Italy, and Sweden are concerned about animal welfare. According to Napolitano et al. [50], animal welfare is becoming progressively significant in the hierarchy of societal matters. As stated by Pirsich et al. [51], numerous consumer studies in Germany have revealed that consumers are eager to pay 10-35\% more for animal welfare-friendly products. According to Rodiger et al. [52], several studies have demonstrated consumer willingness to buy meat and milk and pay more for outdoor access of farm animals, besides, studies have also shown that currently in some European Union countries, consumers have only a limited choice, either organic or traditional products.

According to the Georgian Government report in 2017 [53], the use of antibiotics in animal foods may generate resistance that can be transmitted to humans eating milk or milk products. Georgia, with its nonstop work to achieve the EU food safety regulations standards, has focused sharply on improving animal husbandry and improving the feeding [54]. The lack of adequate feed and shelter during the winter months causes severe problems in milk production and quality, especially in the absence of hygiene, sanitation problems, and animal diseases. Therefore, farmers do not benefit from better prices; this results in a sharp decline in the supply market [11].

In the dairy sector, to produce an appropriate amount of milk, feed considered as the main input for livestock, and families that own many animals use their farms to provide enough grass in summer, maize, hay, and straw in winter. They are unable to guarantee the necessary feed proportions for their animals due to the shortage and high cost of concentrates $[9,17]$. 
Therefore, the productivity of their animals is low. Still, the owners of big farms and large enterprises, as in Kvemo Kartli (our research area) and eastern Georgia, depend on purchasing the necessary feed (such as wheat, corn, and straw) [11]. Moreover, according to CARD [17], the import of animal feed is increasing. In 2017, the index was two times higher than in 2009, providing farmers with the opportunity to secure their needs and take care of their animals. But feeding high amounts of concentrate, such as wheat and soybeans, is not ethical, because this is not according to their physiology and will cause illness such as mastitis [55]. Also, some farmers try to treat their cows with antibiotics in advance to prevent illness which will cause a problem for humans [56].

\subsubsection{Dairy Value Chain Based on Cultural Identity}

In addition to what has mentioned, dairy products are very important to Georgian cuisine. One can see how important the value chain is and specifically concerning traditional Georgian food products that reflect the rich natural identity of the country, especially in the post-Soviet period $[57,58]$. Farmers and processors are the protectors of this food heritage and they have deep knowledge of this heritage. The value chain plays a vital role as an engine for rural development on the one hand, and on the other hand, paves the way to raise the awareness of stakeholders, practitioners, and investors about how to sustain production and develop it in a manner that preserves National Food Identity [43,44].

Based on FAO [59], Georgia is a country which has many precise regional and traditional products with durable territorial identities. Because of this, in 2014, the European Union developed a project to support many countries in this field-and Georgia is one of them.

Wine and cheese were among the most important belongings, which the European Union cared for in Georgia. As these two types of cheese (i.e., Megruli and Sulguni) were especially described as being a significant cultural and traditional heritage in the country. Institutional arrangements in Georgia have been formulated according to the system of geographical indications that operate in the European Union, with the protected designation of origin (PDO) and the Protected Geographical Indication (PGI) as classifications of listed products, in addition to the traditional speciality guaranteed (TSG). Georgia has to protect the names, quality, and exact nature of recorded products [59]. Besides, in 2019 EU funded a new project with a budget of 1.5 million euro, which aims to provide sustenance to the development of "Appellations of Origin (AOs)" and "Geographical Indications (GI-s)" structures in Georgia, and this project will last until January 2021 [60].

According to the FAO report [61], the traditions of Georgian cheese production are linked to the traditional knowledge and traditional cultural expressions and dates back over 80 centuries. It is listed among the top 10 cheese producing countries. It produces around 250 different cheeses. As each type is distinguished by a different texture and flavour, the figure below (Figure 7) shows how the historical-ethnic areas of Georgia developed their varieties of cheese and cheese cultures.

Also, Georgia owns a non-profit organization, "Slow Food Coastal Georgia", which is part of the global Slow Food International movement that is working in more than 160 countries, where volunteers (mostly consumers, farmers, processors) are working in this organization trying hard to inspire society to change towards good, clean, and fair food for everyone in Georgia [62]. 


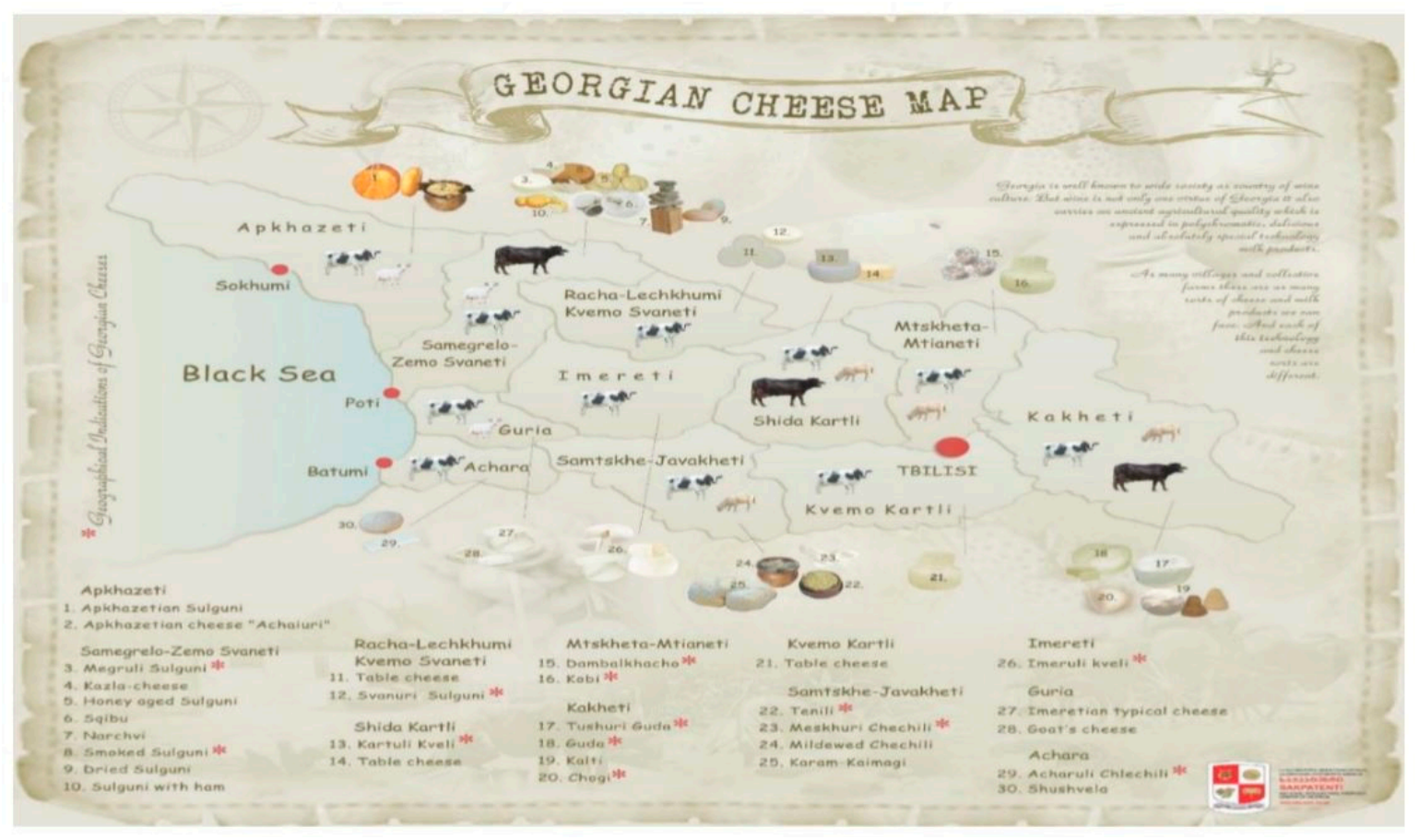

Figure 7. Georgian types of cheese and cheese cultures [61].

\subsubsection{Dairy Value Chain Based on Ecology}

The value chain also means considering environmental standards in the use of resources and directing them to serve the chain. According to the TEEB report [63], the great challenge facing the chain is not only developing a framework that includes eco-agri-food systems based on natural systems but also social policies, economic, political, and interactions among them and within them.

The development of the agricultural sector is highly dependent on ecological services such as managing sustainable ecosystems and conserving water and fertile soil. Unsustainable and irresponsible agricultural practices in Georgia have led to deterioration and depletion of these resources, especially in rural areas, as $60 \%$ of agricultural land has medium or low fertility. As a result, the rangelands deteriorated significantly [63,64]. Based on Withanachchi et al. [65], the use of mountainous areas for mining in Georgia leads to pollution of rangelands. The development of the agricultural sector depends on the process of environmental impact associated with it. According to FAO [61] Korakhashvili et al. [66] Karanja et al. [67] and the department of agriculture in Georgia [68], research in Georgia has proven that the soil is contaminated with heavy metals. Therefore, water contamination leads directly and indirectly to soil pollution, which is the same soil that is used for agricultural production. Animals, such as cows, graze in these contaminated areas and drink the water from creeks and rivers and, therefore, these cows are exposed to these heavy metals. Unfortunately, there are not yet studies which analyze milk from cows grazing on polluted meadows or analyses of the final product, such as cheese. Therefore, damage to it leads to damage to all dairy chain parts. As the agricultural sector in Georgia is closely related to the environmental effect associated with it $[63,64]$.

\subsubsection{Dairy Value Chain Based on Social Factors}

As explained earlier, each component of the value chain has a strong impact on the whole chain which means that considering social issues is essential, and must be addressed, as smallholder farmers in Georgia rely heavily on milk production [17].

But the lack of necessary training, skills, and technical knowledge for them to produce high-quality milk and their inability to control the marketplace put them in the face of many problems. The farmers depend mainly on dairy processors because they lack effective links to the market $[17,64]$. For example, 
the import of low-priced milk powder showed a significant increase in 2016 compared to 2012. In 2016, the milk powder import reached 8334 tons, this was 121\% higher than in 2012 which increased the problems faced by small farmers. In 2017, the entire quantity of milk powder imports increased was almost 9862 tons which was mostly imported from Ukraine (24.7\%), Germany (15.7\%), Belgium (10.7\%), and Belarus (8.6\%) [16,17].

Therefore, as a social factor in the dairy value chain would be to link the smallholder farmers with the market or empower them to produce high-quality and safe dairy products on their farms.

\subsubsection{Dairy Value Chain Based on SDG's}

On top of that, the value chain also means taking into account the globally accepted Sustainable Development Goals (SDGs); these goals encompass 17 goals and 169 targets which were confirmed on 25 September 2015 [69]. Georgia, as a member of the United Nations, was ready to go into the implementation of the SDGs and targets which are set for 2030, as the Georgian government in 2016 incorporated those goals into its annual work plans [70,71].

According to the CARD Report [72], several of the SDGs were significant factors and had the highest impact on developing the Georgian dairy sector.

SDG2: end hunger, achieve food security, and improve nutrition and promote sustainable agriculture [69]. Increasing production and enhancing competition opportunities are among the goals that the Dairy Farmers Association aspire to.

Because they are directly related to the productivity and performance of smallholder farmers, as these associations provide the necessary services to them by obtaining advanced technology and improved breeds that help them cost-effectively increase their production. The rural population depends mainly on dairy products in their daily lives and, thus, will contribute to food security and the elimination of hunger. On the other hand, creating such opportunities will increase the income of dairy farmers. It will be economic support to those regions which serves the first goal of SDGs: end poverty in all its forms everywhere [69,72]. According to CRRC [16], in recent years, many internal and external investments and cooperatives have emerged that are trying to build a bridge between smalland medium-sized companies and small farmers, with the main goals to support farmers to obtain a stronger position in the market. For example, the Alliance Caucasus Program (ALCP), which started in 2008 and entered into force in 2017, was funded by the Swiss Cooperation Authority (SDC) and is being implemented by Mercy Corps. This program runs until 2021 and focuses on the development of the livestock sector in Georgia. The program supports dairy factories for small and medium enterprises (SME) and is establishing a close and sustainable relationship with local communities and smallholder farmers. On the other hand, the smallholder dairy production sector in Georgia is under the leadership of men, but, men and women work together. Besides, women are more responsible to produce milk and dairy products on family farms. Despite this, and concerning the old tradition's, men are always presented to play the main role which made SDG 5 "Achieve gender equality and empower all women and girls" [69] of the sustainable development goals very important, as it also provides women with an opportunity for equality and fairness.

The implementation of the new regulations "which provides for the prevention of agencies that work in milk processing and production from receiving milk from unknown cattle that were not registered electronically in the official records" [6] in 2020, will support the responsible parties for the dairy sector in Georgia in controlling production amounts and raising awareness among dairy farmers.

This leads to achieving a low level of food loss, which is one of the most important sustainable goals, which is SDG 12 "Ensure sustainable consumption and production patterns" [69,72]. As well as the implementation of SDG 17, "Revitalize the global partnership for sustainable development" [16] which is considered one of the main axes of the value chain, as mentioned previously, the consolidation of the relationship between the public and private sectors on issues related to the industry, helps directly and indirectly to play a mediating role between farmers and the government, and thus opening 
new horizons for each of the smallholder farmers and producers, big companies and investors, which has a positive impact on the chain [11].

\subsubsection{Dairy Value Chain Based on Food Quality and Food Safety}

Despite the above facts, the development of the regulatory sector for Georgian dairy foods is one of the most important pillars of the value chain. It should give access to a high-quality product that satisfies both consumers and legislators need strict laws and standards [19]. For example, taking care of animal welfare, good hygiene standards, implementing risk analysis, and knowledge about critical control points in Georgian dairy supply chain and facing the risk of antibiotic resistance, all of which drive the value chain to new stages of development and progress [54].

According to the Europe Foundation report [54], since 2004, Georgia has been concentrated on developing a food safety system in the country, including the safety regulation for dairy products, which changed, especially after the collapse of the Soviet Union. One of the most important motives for developing these regulations was the signing of a partnership agreement "EU-Georgia Association Agreement" between Georgia and the European Union in the year 2014 regarding the food safety system. At the beginning of 2010, Georgia adopted its food safety system, a comprehensive plan, and legislative activities, closer to the standards of the European Union [54]. On 1 August 2015, the technical regulations for milk and dairy products were put into action which, in turn, stimulates a ban on the sale of foods that carry the name "dairy products" and which components do not contain animal milk but are manufactured from other raw materials. Besides, in the same year, the government monitored the milk and dairy production sector to ensure that the regulations entered into force and, thus, protect the consumer from misinformation [54]. The National Food Agency (NFA), a governmental body, which is the major player in the Georgian Agriculture sector, which is the responsible and trustworthy actor for regulating food safety, is in charge of checking the output of food products compared to the data provided on labels. It has spotted many cases where laws were violated [73]. The Georgian government is working unceasingly to develop and improve the food legislative framework which, in turn, is responsible for solving problems in the livestock sector. This should lead to obtaining a safe milk source based on the existence of healthy livestock. The responsible authorities, through the electronic animal registration database, develop the monitoring of all related dairy systems, including vaccination programs for the livestock sector [6].

Moreover, at the beginning of 2019, new laws were developed. The aim is the traceability of the value chain and transparent processes. This law came into force in 2020 to prevent the agencies that work in milk processing and production from receiving milk from unknown cattle that were not registered electronically in the official records. Whereas, in the year 2020, food producers will be obligated to be listed as business operators which, in turn, will solve the problem of non-registered enterprises and family farmers at the governmental level [6].

\subsection{Results of Expert Interviews}

\subsubsection{Participants Statements of the Dairy Value Chain in Georgia}

Supporting the value chain economically is not an easy process. Many experts emphasized that the government's role in supporting dairy production in Georgia is diverse and highly controversial. The government support for different sectors is widely discussed by the interviewees.

The provision for veterinary services is the only way that government support is reaching dairy farmers. Other sectoral support includes the market or when the production is limited which, in turn, hinders the development of the chain to some extent.

The following interview mentioned this issue clearly:

"G1: The government provides the farmers just with veterinary services; also, we are doing the vaccination free." 
Besides, according to other experts: "Imported milk is cheaper than Georgian milk and is used from the dairy producers to make cheese and other products, and that is a big problem for us and our economy. The farmers, in this case, are not supported."

The government is trying to support all aspects of the value chain. Regimes are seriously trying to control the health of animals, because they are vulnerable to disease which, in turn, poses health risks to the entire population - especially considering that dairy products are of heritage importance and is considered one of the most popular national foods, as the government's views indicate this aspect.

"G2: These associations have veterinarian doctors all the time, and these cows sit in stations, so they don't go out to the field, so they always kept there, but no idea how often the veterinarian is checking them, and the cows are completely healthy and the get a good treat with medicine and everything regularly, and there is no chance for them to get sick because they are always inside."

"DI1: We have food safety control, and it will be done by NFA, and they are controlling everything, but about export, they cannot do anything now, but we hope in the next five years all will be better, at least now we can export wine, honey, and tea, etc. (Products without animals)."

However, the government technical staff denied such an argument. They revealed that the government is supportive of education and knowledge building in the dairy sector. They are getting support from the EU and other international donor agencies to advance their technical support to the farmers:

"P1: Yes, we are trying to supporting them with most knowledge, training, we are not supporting them with funds for example 5000 Lari, and they will use it to buy a car for their son, they are just asking for money, and they thought they don't need any training on food safety issues, they said my father is always doing that, so it is hard time for us to persuade the donors as well as the government that our aim to do something to keep the food otherwise just spending this 15.5 million on particular persons who are not willing to have any training and just be handed makes no sense."

"DI1: That is why education is very important, because they are lazy, and they want to live in good conditions but without having any control. They are crying that the government is not helping them. However, when they come to help, they are refusing that help."

Enabling relationships and cooperation with companies outside Georgia to support the value chain helps open several avenues for the advancement of the dairy production sector, and this international collaboration provides financial support to the existing government program. US Aid is one of the key supporters:

"G3: There is no time frame for this training it depended on the farmers when he asked us to come to his farm and give him some help and also some different organization like from the US, and they are supporting for free the farmers (14 million projects)."

The import of milk and milk powder in Georgia is one of the most significant causes that damage the dairy value chain. It is increasing year by year and exceeds export, ensuing in undesirable trade stability of milk and milk products. In terms of amount, Georgia's export of milk and dairy products is very limited. However, according to experts, many cases have confirmed this concern:

"G4: For example, the imported powder milk from the neighbour's countries, it is cheaper than Georgian milk and is used from the dairy producers to make cheese and other products, and that is a big problem for us and our economy." 
"P2: for example, let's say, the coast of milk in Georgia is two times higher than the imported one based on our survey, which we made almost in all country, and that is unfair competition."

"G5: Georgian dairy production coast is higher than the imported one also, as we told you before, most of the big producer is using imported powder milk, and it is much cheaper than Georgian milk."

This increase in milk and milk powder import demand remains in the opinion of experts, the key driving force for moving the Georgian local dairy market backwards. The experts view mentions this aspect:

"DI2: We are importing milk and milk powder to the country because our production is not enough, and we can cover just 30\% from our need, and this 70\% from all DP is imported especially milk powder."

"P3: In Georgia, the milk products which in the whole markets done by milk powder, so almost $75 \%$ from the whole production and this milk powder imported into Georgia."

On the other hand, the experts stressed the importance of traditions in developing the chain and the problems that it suffers from and how to benefit from it and implement it under the new regulations where one of the experts stated:

“IO: This grandmother made real cheese from milk, but she doesn't have any hygiene so she never follows any hygiene steps, for example, you must pasteurized milk and then making the cheese so from the milking to making the cheese (a lot now in Georgia are using milk powder) no hygiene at all. Sometimes, if they are boiling the milk, the milk will lose his substance and is hard then to make the cheese, so they are not boiling, so from the row milk you have a lot of problems, bacteria, etc.), so this cheese is for home consumption, but if they have some more, and especially in this period, they will sell it. So, they will go to the Bazar and unfortunately it is not controlled yet by the government because they will be allowed to control the grandmother's place from 2020 by NFA and they will check the place so it will be much easier."

Another expert also stated that other traditional methods are used to this day, and if they are taken advantage of and applied, it may provide special character to the value chain:

"DI1: Another art of cheese is made in a very strange way, they will prepare the cheese and its hard cheese, and then they will add butter and salt; later on, they will put this cheese in sheep stomach (empty one) and push it to animal tactical or stomach. Then roosting this cheese and make it like sausages. And they are storing it for 3-4 month under the ground until they sell it (cheese name: Karam Kaimagh - Mtskheta region)."

All experts agree that animal welfare is one of the most important facts of the dairy value chain. In addition, farm animal welfare is reliant on human care. Farmers in the Georgian villages make decisions on housing systems and how they are managing it. On the other hand, the government is trying to apply dairy farming regulations all over the country, and they are facing many difficulties concerning smallholder farmers. One of the experts mentioned that:

"P2: The problems we are facing in dairy farming are a lot, first of all, we have very bad conditions in the barns and the cows' situation there is really bad, the government controls normally just the production sector, they are controlling where they are producing milk or cheese or another product, but they have no idea what is happening in the barns."

The farmers in all regions were not always aware of their animals' health problems. For example: "DI2: Another thing they are receiving the milk from the farmers and the farmers have no idea about 
their own animals' health condition." Supporting the value chain, the government formed several policies to support dairy farmers and drive the dairy sector forward, as one expert noted: G6: Every month they ask this forum from the farmers which proves that your animal has been checked and they are healthy."

Considering that farmers and veterinarians have a precise responsibility in affecting animal health, still, few farmers took sick animals to a veterinary centre for treatment; the remaining farmers depended on traditional treatments. One of the experts mentioned that: "G7: Also, the animals must get treatment, and in the best condition, which is not the good thing in Georgia if you visited the field, you will see the animal welfare situation."

The government sees that the marketing chain of milk and milk products from smallholder farmers is carried out in an unorganized way; one of the reasons is due to the traditions used in the villages.

In the Georgian milk market, we can recognize two different marketing structures:

1. Traditional village systems, where milk from farmers is sold on the opening market, restaurants, and/or groceries as within the region or by using middlemen. As one expert noted:

"G6: Another case, there is a third party like a farmer that takes the milk and delivers the milk to a second person who is dealing with the companies and the producers who are making cheese. But still very few cases and normally it's like official agreement."

2. Milk collecting points; in this approach, the milk will be collected from the farmers for processing and marketing by private companies.

Therefore to mitigate challenges that limit productivity, the government and the private sector are working hard to support the smallholder dairy farmers along the dairy value chains and develop pertinent and suitable strategies to alleviate the difficulties which facing them and improve dairy production and marketing systems in Georgia, experts stated that: "DI3:...they are receiving and buying milk from farmers, our main beneficiaries are farmers, but we are working with farmers role services providers, we are the program which implements an approach we are creating the market for poor people, in this case, the farmers."

However, based on experts, the Georgian milk, which costs the customers and the producers more than the imported one appears to be unpopular with Georgian dairy sector: "DI4: Georgian dairy costs more than the imported."

Nevertheless, the Georgian government is trying so hard to control the dairy farmers by selling their milk without any food safety measures which leaves consumers questioning product quality, the food regulatory experts mentioned:

"G8: The smallholder farmers they cannot be controlled completely, there is a market and supermarket (where you are sure everything safe) but the other one called the Bazar and there the cheese from the farmers have been sold, and you cannot be sure at all if this cheese is safe or if they are contaminated or with different diseases, and that's because normally these farmers are not allowed to sell their product in the supermarket so they are standing on the road or in the Bazar to sell their cheese and own product and here no one will tell them anything or make any control on them."

“G7: Right now, you can see small supermarkets, there are people who opened their small business, and the farmers are going there to sell their products, so the main cheese."

Furthermore, they need to improve the safety of dairy farms in traditional societies. It plays an important role in the chain, including supervision of good practices in animal feeding, hygiene, and animal husbandry; the local indigenous farmers are the major actor, those are in most instances not aware enough of the value of their indigenous knowledge which has been transient from generation after generation. 
Currently, in Georgia, there is a crucial need for this information through government support and development actions; some of the experts reveal this situation as:

"DI5: In the old times, we were always working in the cleaning process, like cleaning hands, and all safety processes by milking or other steps in dairy products, but now it is different. In Georgia, when we are preparing cheese, we remove hair from the hands completely, but now it is not anymore about removing the hair, they do not even wash the hands."

Based on the expert's views, the following key area could be noted:

"DI4: For example, there is a farmer, a woman, she has two cows, she has some implication on her fingers, and with these hands, she is not allowed to milk the cows. The first time she put some plastics cover to protect the cows, but later, she removes it and continues milking the cows. Therefore, it does not matter how many times we are telling her about that, and she never listened to us until we told her story on TV, and she was ashamed, then she removed that disease from her hands."

Also, the government's attempt to support the chain from an ecological perspective, the Georgian government looks forward to initiating organic farming in the dairy food sector. The new proposal wrote to get the money for such a project: "P3: Now the government wrote a new project which it will support the organic sector in Georgia, it's like they will pay $80 \%$ for certification, for example, if it costs 1000 Lari, the government will pay 800 Lari, and they will also buy organic fertilizer for farmers."

The current food quality and food safety situation of the Georgian dairy value chain was clarified from the perspective of the experts. It addressed the current dairy situation, constraints, and regulations. According to the experts, the dairy sector in Georgia has weak food safety systems in terms of required infrastructure, qualified human resources, food safety culture, and enforceable regulation which, in turn, reflects negatively on the chain.

One of the explanations for these conditions is limited farmer awareness about animal diseases and food safety standards on their farms and their significances in terms of health risks for farm households, consumers, and the whole society:

"P1: The problem is very low awareness; they don't know about hazards from hygiene condition, food safety hazard; you have to tell a lot starting from feed safety, cleaning, hand washing, storage, temperature of milk. they know almost nothing about these kinds of things; you have to start with very simple things to explain."

Internationally recognized safety systems are used to maintain food safety and quality in the dairy sector of Georgia. The level of seriousness of adaptability or applicability is not well-represented in the total dairy value chain. The expert views reflect two sides of argumentation in this regard. One argument is that the difficulties in the implementation of such an international safety system due to the lack of willingness of stakeholders or the lack of formalities in the dairy food value system. Another argument is that the fragmentation within the general food regulations in Georgia. One expert (N3) expressed this issue as:

"P2: If a producer is officially registered then, this food business operator must implement good hygiene requirement, and there is a piece of legislation, government regulations 1-7-3, also this kind of producers must implement HACCP principles and also there is a technical regulation for milk and dairy products, and there is also a different piece of legislation regarding microbiological requirement for food, on a legislative level, the situation is quite good, the problem is the implementation of this legislation and control."

Still, some experts have a positive view of the adaptation of the international food safety system. For example, the HACCP - (Hazard Analysis and Critical Control Point) is applied to minimizing the risk of safety hazards in dairy products. The view of a group of the expert is 
"DI6: Almost all the dairy factory where they are working they have HACCP, is HACCP certified, and they have records, we started working with cheeses factory's to help them upgrade their equipment and be compliant according to the national and international requirement of HAACP and other food safety requirement."

However, the connectivity between sectors is a crucial factor in the line. If the HACCP is not practically implemented and not monitored, food safety cannot be expected, said the experts. The food regulatory experts mention:

"DI4: There is a lot of requirement which that the factory should meet; for instance, milk should be collected from the farmers and must be raw milk. The factory must have HACCP, not in a paper factory must fallow requirement which rotating to HACCP documents."

Therefore the safety and quality of dairy products should be ensured to protect the consumers, especially sensitive categories such as children and pregnant women, but according to the expert's farm hygiene, it is not the only underlying problem in the dairy sector, if environmental cleanliness is involved, its influence is probable to be small relative to the growing effect of these other issues. For instance, the contamination of heavy metals:

"G8: In Kvemo Kartli the most interesting thing is that they have the mining companies who are digging for gold and others precious stones so these companies are exploring the mountains and digging there so it can happen there is a lot of metals in the ground or soil or water, so that's one of the interesting things. And they checked the river Masha Vera, and because of washing the gold inside this river, they analyzed the milk from the cows and soil, and they found heavy metals there, and the main was in the downstream area."

On the other hand, it is remarkable that not all the government sectors are on the same page, what concerns the heavy metals contamination because they do not evaluate the situation as being problematic or affect the value chain directly, few experts explained that the dairy sector does not face a significant health risk from trace metals: "G9: I think we had not such a case with milk or dairy product where we found to exist of any HM, but it's difficult to say, and not just in milk also in meat." Other experts pointed: "G5: In Kvemo Kartli region, they did not find any trace of the heavy metals at all just in the west part of Georgia almost 15 cases when they found lead in the products."

However, according to the experts, particularly important cases have lately confirmed this concern:

"G10: There was a case in Georgia about spices, and some persons made an analysis in Turkey and found that it was contaminated with a high amount of lead, and then the National Food Agency made a risk assessment, then they prohibited selling spices because there were no traceability for the product, that is why and afterwards the investigation of lead became popular also in other products."

"DI1: Example When the bees were contaminated with heavy metals, we did first the analysis in Ukraine then we decided to do it in Germany, it is too much expensive for us, but you know they are professional, and we trust them, and normally we did all laboratory analyses in Germany, but when we tried Ukraine, it was a huge difference according to the prices."

"P3: The next problem is water, sometimes the cows are drinking from the streets or the close rivers; for example, in Bolnisi the cow are drinking from the river there and it is common that it is contaminated, but the problem is that they have no other option. At night, the farmers are giving the cows just a small amount of water because the water resources are so far from the farm, and it is a big problem because the milk production is dependent also on the water."

To ensure a high quality of dairy products and improve the dairy value chain, it is necessary to precisely and quickly monitors the individual production steps so that they can be quickly corrected 
and optimized. In the Georgian case, the National Food Agency is responsible for dairy production quality control: "G9: About control, the production it must be done by the National Food Agency."

However, based on experts, currently, there is no quality control at all on-farm level: "P1: There is no control for primary production, farmers (small families) are not controlled at all."

In the villages, farmers still milking cows by hand without using any milking equipment or hand and udder protection. The production on farms is still primitive. Farmers are not aware of the feeding practices and the use of storage techniques or equipment for ensuring the safety and the quality of milk:

"DI4: ... but I am not sure, but animal food is not controlled at all, there is no legislation for this, it can be imported, or made in Georgia without any legislation or control since there is control everybody tries to have the feed which also contains antibiotics and Microbe's in order the animals to be in the safe side."

It is a big challenge to control the dairy production chain. This sector is facing different serious issues like low production, non-existence of modern equipment and technologies, and lack of management practices: "DI6: The main focus is about safety [rather] than the quality because quality is more difficult in the country to control and implement because of the lack of veterinarian services in the country, this very painful."

The experts also mentioned: "G11: In the food safety sector, Georgia wants to be a long time ago more closely to EU Regulations. Therefore, there is a basic hygiene requirement for dairy production and a new regulation for that."

Georgia is working hard to implement the sustainable development goals, including strengthening relationships and investments with other countries, to develop the value chain, for example, Georgia at the stage of a new partnership with the EU, the reaction for the new structures has been identified by the experts in the dairy products sector as follows: "P3: About EU regulations, first, we must fix some of the rules and regulations inside the country then, later on, we can think about the EU regulations, you know EU have their cheese and a lot of milk production compared with Georgia." Also, "P2: The European Union concluded Association Agreements (AAs) with Georgia, the Republic of Moldova."

"P1: We signed an association agreement, and we have a DCFTA agreement (Deep and Comprehensive Free Trade Agreement) with the European Union, and the Government undertakes the obligation to implement EU legislation in Georgia when this process started in 2006, and it will be finally finished in 2030 I think, step by step on a legislative level we have implemented several EU documents and this process is quite supported by the government, but then the problem was to implement and control. On paper, we have quite a good situation, but it's very difficult because of a lack of knowledge, lack of education, lack of resources for control, lack of inspectors; there is always no control on the primary level, farmers level, only registered more or less small and middle producers controlled but there are a lot of areas that are not controlled."

Besides, one of the most important goals in the SDGs is to end poverty which in turn brings positive results to the chain. For instance, the Georgian government opened its agricultural and food markets and decreased its role within the dairy sector. Large dairy enterprises and other private sectors increased their investments in dairy facilities and equipment which caused, for smallholder farmers, mostly economic losses, as one expert noted: "DI2: Small hold farmers, the poor ones, which have 1, 2 or 3 cows, what about them? How do you think it is possible to give this farmer the awareness or the knowledge and solve their problems?"

Moreover, for the government, it is important to support the development of small-scale dairy production to serve the local markets. Using the milk powder and increasing investment of private companies in milk production threatens the local milk markets and the existence of smallholder farmers, one of the experts mentioned that: "DI3: We started working with them and develop the other services for example support services (feeding veterinarian services, food safety, breeding, etc...)". 
Besides, the government believes that next to everything it offers and all its efforts, there is an enormous gap among these three parties: government, smallholder farmers, and the private sectors. Farmers also felt there was unused functionality in their political system and that they could profit more from increased support from both the government and the investors. Dairy industry companies want to take the lead in constructing awareness of modern dairy production while facilitating admittance to free information about technology competence and investment. For instance, one of the experts mentioned that:

"DI4: Also what I see is a gap of a common platform of private and the state, sitting and making decisions, this is a problem that the government makes a decision based on something, maybe on wrong ideas, and this has not been discussed with the private sector, the private sector is going forward and getting smarter, so the government has to go also in this way with a better strategy."

Another stated: "G2: We have contact with the private sector but not a big deal." Other experts noted:

"G1: The National Food Agency is the official body that belongs to the government and provides official control, and there is quality food control and food safety control cooperation with the private sector and also quality management because it is our tool control to check inside the companies because the marketing standard has the same conditions from food safety."

Nevertheless, the farmers and the private sector are still focusing on their interest in the production chain, despite all the problems they face; experts stated that: "G8: So, usually the case is that the companies are dealing directly with the farmers, so the farmer will collect the milk for the cows and delivered immediately to the producers because with the third party it is not working at all."

\subsubsection{Summary of the Empirical Study with Experts in the Dairy Supply Chain}

This study aimed to examine the dynamics of the dairy food value chain in Georgia, scrutinize the current dairy production safety regulations and policies, and to find out which kind of socio-economic impacts occur for smallholder dairy farmers marketing their products.

Thus, this study successfully outlined the differences between the dairy value chain factors, and how each of these factors plays an important role in achieving the balance among all parties in the chain and developing its work. Farmers and processors in Georgia are using diverse strategies to compensate for the absence of proper arrangements. One example is that the government does not see the importance of some factors in the value chain, such as the Slow-Food "Value" (heritage value) for the farmers and its connection with food culture practised by consumers, combined with ethics in Georgia.

For the moment, the current dairy value chain provides these farmers with just a source of employment and a small share of the entire family income. Furthermore, the most important goal that must be focused on is to integrate smallholders in the dairy sector with the private and public ones. This coexistence provides a balanced mechanism of action within the chain. It makes it easy to integrate sustainable development goals with the other value chain factors which, in turn, leads to the advancement of the current situation to a new step of success. The development is creating a competition in milk supply which causes rapid growth in both supply and demand for milk. This growth encourages food production (such as cheese) that is more dependent on social, cultural, and ethical factors. 


\section{Conclusions and Discussion}

\subsection{Summary of the Literature Results}

The value chain, as the results of our literature study, demonstrates the full range of factors and activities needed to create a particular "valuable" product. The dairy value chain includes the steps necessary to transform the product from just an idea to being distributed and reaching the final consumer. The primary goal of the value chain and its analysis is to provide the greatest possible value and create a competitive advantage.

The concept of "value" here is intended to include not only economically but also culturally, socially, environmentally, ethically as well as health-based aspects from production to consumption. It is an integrated concept that cannot be divided. It supports the concept of internalizing external effects. Every activity or passivity of one object creates external effects that affect another entity. These effects can be positive or negative. The goal of internalization here is to optimize the welfare level of all participants in the chain (e.g., society) and the entire economy and to include the social costs caused by the effect in a total cost calculation. Besides, internalizations are assessed according to (ecological) effectiveness and economic efficiency [74,75].

Thus, considering all aspects of the economy will help to support the value chain and create a balance between its components. It helps to build a bridge between the processors, smallholder farmers, and the big companies, and it also assists in strengthening the relationship between the private sector and the public one. All this creates job opportunities and will help farmers to be engaged positively in the process of economic development, thereby increasing the capabilities, assets, and activities available to families to generate income.

The value chain also depends directly on the ethical concept. For example, the value chain for milk relies on animal health and animal welfare. This includes their handling, feeding, and how clean the sheds are used and protecting these animals from diseases, risks, and support control. On the other hand, the social factor plays a fundamental role in developing the chain, like gender equality, supporting the young people, smallholder farmers, and community development. All of this helps to improve the ability of community members to join their efforts to take collective actions and find solutions to common problems which, in turn, are positively reflected in the chain's work mechanism. The cultural factor in which food value chains operate is an essential component. The consideration of language, religion, ethics and traditions, education, entrepreneurship, history, and attitudes are related to the methods commonly used in food production, processing, distribution, and preparation at home. Also, maintaining the health of ecosystems and making optimal use of the available natural resources, and not damaging them, significantly affects the value chain. Carbon- and water footprints, plant and animal health, pests and weeds, biodiversity, soil, and water health are all directly related to the stability and development of the chain. In addition to all of this, the sustainable development goals (SDGs) stipulated by the United Nations are an essential pillar in developing and supporting the value chain.

The food safety and quality regulations followed and stipulated directly affect the food value chain, the quality, and safety of food must be preserved, and the use of substances that may negatively affect production, such as powdered milk, must be limited. Therefore, the safety of all steps of the product from the farm to the consumer must be monitored, a clean work environment, milk collection, and storage operations and all necessary laboratories must be controlled which guarantees the safety and quality of the final product.

\subsection{Graphical Results}

Figure 8 illustrates all the factors covered in this study which were discussed through expert interviews and which presented some of the main challenges facing the dairy value chain in Georgia. 


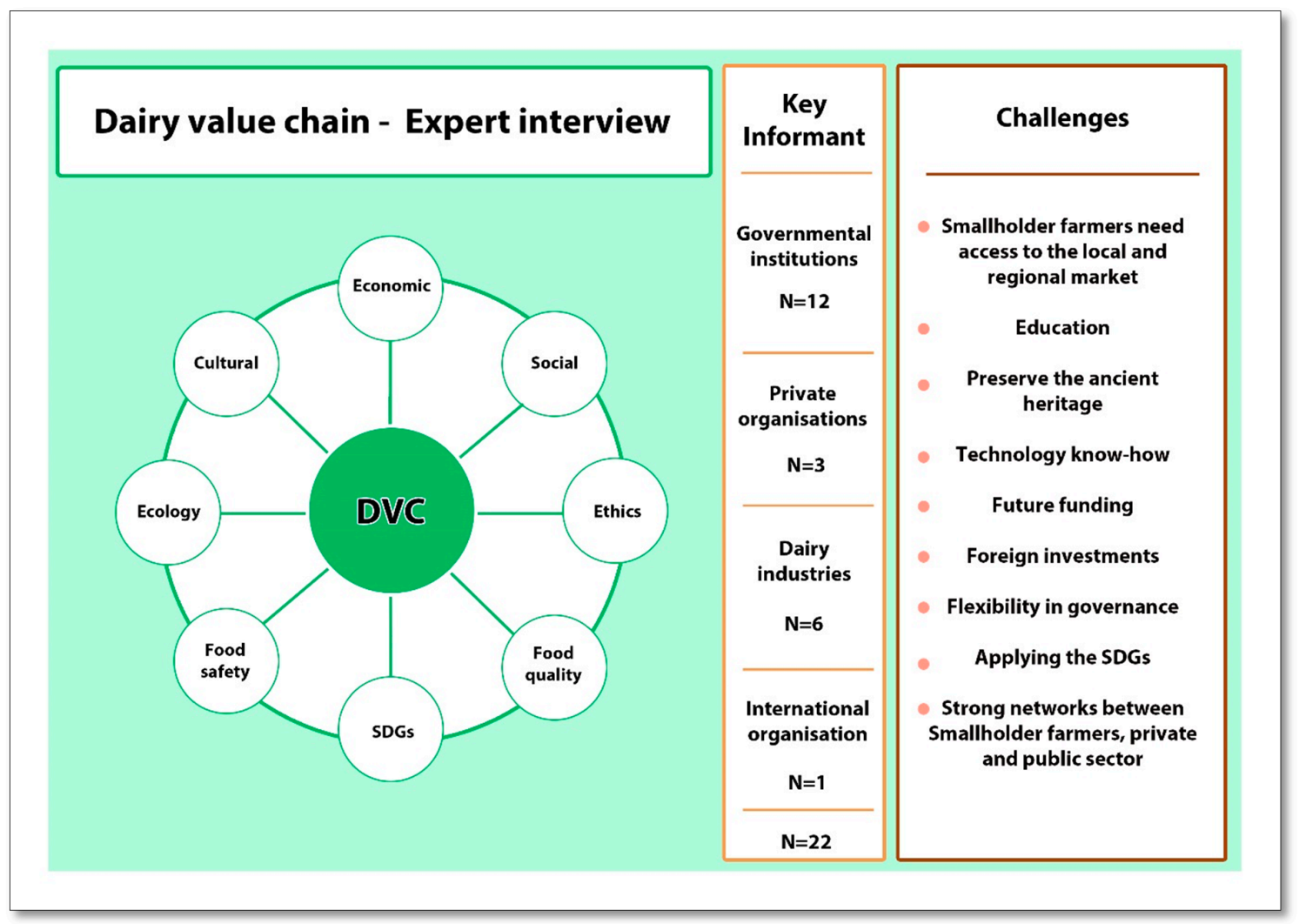

Figure 8. Graphical results of the expert Interview.

The results of this research have shown that the structure of the dairy value chain in Georgia is closely related to the efficiency and level of integration of all the factors that make up this chain.

The results also outlined the differences in expert opinions in assessing the status of each of the elements of the chain.

As the study outcomes show, the marketing issues, for instance, take a lot of attention from the private sector compared to the public sector which did not pay much attention to it, as this aspect was mentioned during the interviews only a few times from the governmental side, while the majority of non-governmental parties talked about it at length. On the other hand, the government side focused more on how to provide support to farmers to try to include them in the current agricultural political process.

Where the literary studies have proven that economic and agricultural policies are the cornerstones of the value chain, also the government support to the farmers must consider all aspects, without limitation, which supports the chain and builds a solid bridge for cooperation. Especially after Georgia has experienced major economic difficulties since the collapse of the Soviet Union, it is necessary to see the fundamental transformations in the working systems to see the initiatives, that have been successfully developed and maintained to build or improve the value chains [45,46].

As Willett et al. [76] conclude, farmers subsidy programs, which support the rural economies and should help to create the balance between food prices and food safety and quality, play a major role to reach a sustainable value chain, as smallholder farmers are the main contributors to maintaining public health. This means that all stakeholders in Georgia, including the government, have to make an additional effort to build a sustainable business model with a long-term commitment which will lead to a stable value chain, aiming to compete more effectively.

The results obtained from this study partially support the results of previous studies that indicate an important role for the ethical factor in developing the value chain and its impact on all different elements within the chain. But experts did not have the same opinions about the importance of animal 
welfare and on the necessity of consumer awareness of food quality and safety. As stated by the Nuffield [77] report, the ethical framework for public health needs to include social values, through which we can meet standard health needs and elevate them to reach sustainability.

Also, this study identifies that one of the challenges facing the chain is the development of ecological services in the agricultural sector. Springmann et al. [78] and Tilman et al. [79,80] indicated that the increase in demand for animal products negatively affects land use, leads to increased greenhouse gas emissions, and irresponsible animal feeding programs using grains or pastures which negatively affect water wealth. However, responsible animal production is necessary to alleviate poverty, support livelihoods, and environmental services in the grassland [81]. Therefore, the optimal use of feed and animal welfare affects the value chain positively in environmental contexts [82].

The study also showed how important it is to implement SDGs to develop the value chain in Georgia, as it is a shared responsibility of government authorities, civil society, and the private sector [71]. As the ICSU report [83] emphasized, it is important to work on developing rural infrastructure and integrating small-scale enterprises into the value chain, supporting investment and sustainable agricultural programs. In addition to maximizing the overall social, environmental, and ethical impact, building communication between companies and direct suppliers is necessary. All these aims should be reached to achieve the SDGs in a way that ensures the sustainability of the dairy value chain and implementing the SDGs.

In conclusion, this study explored the factors that influence the efficiency of the dairy value chain and how to evaluate and develop its factors. It also presented the importance of the interaction among the components of the chain and all parties belonging to it, and how the efficiency of the value chain is closely related to food safety and quality. It also showed the extent of the involvement of the ethical, cultural, and social aspects in the success of the work and balance of this chain. It also outlined the positive aspects of applying SDGs to the value chain and how important they are in political, economic, and environmental decisions. These results may help develop the dairy value chain in Georgia and develop an appropriate plan for each of the elements of the chain, where all actors should take into account all factors and continuously coordinate and build among them to ensure the sustainability of the value chain.

\section{Further Work to Do}

Future studies in the Georgian dairy sector should provide more quantitative statistics on dairy smallholder situations. Such studies should focus more on the causes of low-quality milk production and its relationship to the value chain. More details should be provided on how smallholder farms could be associated to the current dairy regulations. It will also be of great importance to take the gender, ethical, and cultural identity viewpoints into consideration for future studies.

Author Contributions: R.A.S., T.U. and A.P. conceived and designed the experiments; R.A.S. wrote the manuscript of the publication; A.P. supervised the working process. All authors have read and agreed to the published version of the manuscript.

Funding: This research study is a part of the cooperative research work between the University of Kassel, Faculty for Organic Agricultural Sciences, and the Agricultural University of Georgia since 2018. The VW Foundation financed the research project "Structured PhD-Program on Sustainable Agricultural and Food Systems" (SAFS).

Acknowledgments: The authors would like to thank Olga Olashyn for her contribution in the literature part, especially for the translation of Russian documents, and the anonymous reviewers for their helpful comments.

Conflicts of Interest: The authors declare no conflict of interest. Besides, the funders had no role in the design of the study; in the collection, analyses, or interpretation of data; in the writing of the manuscript, and in the decision to publish the results. 


\section{Appendix A}

Table A1. Literature Review Keywords.

\begin{tabular}{l}
\hline Dairy value chain \\
\hline Value chain \\
\hline Supply chain \\
\hline Dairy supply chain \\
\hline Georgia \\
\hline Dairy value chain in Georgia \\
\hline Supply chain in Georgia \\
\hline Dairy \\
\hline Milk value chain \\
\hline Milk value chain in Georgia \\
\hline Milk supply chain \\
\hline Milk supply chain in Georgia \\
\hline Cheese value chain \\
\hline Cheese supply chain \\
\hline Georgian cheese \\
\hline Dairy products \\
\hline Food safety \\
\hline Food quality \\
\hline Georgian food regulation \\
\hline Georgian dairy regulation \\
\hline
\end{tabular}

\section{References}

1. Bernabé, S.; Stampini, M. Labour Mobility During Transition. Evidence from Georgia. Econ. Transit. 2009, 17, 377-409. [CrossRef]

2. Lerman, Z.; Csaki, C.; Feder, G. Agriculture in Transition: Land Policies and Evolving Farm Structures in Post-Soviet Countries; Lexington Books: Lanham, MD, USA, 2004; ISBN 0739108077.

3. Terra Institute, Ltd. Georgia Land Market Development Project Final Report; Terra Institute, Ltd.: Blue Mounds, WI, USA, 2005; Available online: http://www.terrainstitute.org/pdf/Georgia_LMDP_Final_Report.pdf (accessed on 18 June 2020).

4. Pignatti, N. Demographic Structure, Labor Market Conditions and Stalled Agricultural Development in a Post-Transition Country; Tbilisi State University (TSU): Tbilisi, Georgia, 2017.

5. GeoStat National Statistics Office of Georgia (GeoStat), Tbilisi, Georgia. 2014. Available online: https: //www.geostat.ge/regions/\# (accessed on 20 April 2020).

6. Gelashvili, S.; Deisadze, S. Difficulties of Implementing the Technical Regulation on Milk and Dairy Products; ISET Policy Institute: Tbilisi, Georgia, 2019.

7. EI-LAT. The Economic Transformation of Georgia in its 20 Years of Independence. Summary of the Discussion Paper; Liberal Academy-Tbilisi: Tbilisi, Georgia, 2012.

8. Gvaramia, A. Land Ownership and the Development of the Land Market in Georgia; ALCP Study: Tbilisi, Georgia, 2013.

9. Raaflaub, M.; Dobry, L.M. Pasture Management in Georgia. Current Situation, Frame Conditions, Potentials of Development; Swiss Agency for Development and Cooperation SDC: Bern, Swiss, 2015; Volume 42.

10. ALCP. Ensuring Sustainability in the Dairy Market Sector; Swiss Agency for Development and Cooperation SDC: Bern, Swiss, 2017.

11. Republic of Georgia. IFAD Dairy Modernisation and Market Access Programme (DiMMA): Final Project Design Report; Republic of Georgia: Tbilisi, Georgia, 2018. 
12. Weidman, T. The Woman Saving Georgia's Lost Cheeses. Available online: https://forbes.ge/news/7609/TheWoman-Saving-Georgia \T1 \textquoterights-Lost-Cheeses (accessed on 2 April 2020).

13. ALCP. National Cheese Sector Research; Swiss Agency for Development and Cooperation SDC: Bern, Swiss, 2016.

14. ALCP. Analysing Systemic Change Trends in the Dairy Sector; ALCP: Marneuli, Georgia, 2018.

15. Gonashvili, B.; Mosiashvili, M.; Sisvadze, N. Perspectives on Sheep Farming E The Sheep Market System in Georgia; Swiss Agency for Development and Cooperation SDC: Bern, Swiss, 2013.

16. CRRC. Dairy and Beef Consumer Preferences; Caucasus Research Resource Center: Tbilisi, Georgia, 2018.

17. CARD Baseline Assessment of the Dairy Sector in Georgia; Center for Agribusiness and Rural Development: Tbilisi, Georgia, 2018.

18. ALCP. Better Cheese, Better Work. International Labour Office: Georgia, 2020. Available online: https://www. ilo.org/wcmsp5/groups/public/---ed_emp/---emp_ent/documents/publication/wcms_746235.pdf (accessed on 2 April 2020).

19. Europe Foundation. Food Safety Regulation in Georgia: Assessment of Government's Reform Efforts in 2015; Europe Foundation: Tbilisi, Georgia, 2015.

20. Neven, D. Developing Sustainable Food Value Chains; FAO: Rome, Italy, 2014; Volume 25, ISBN 9789251084816.

21. Gómez, M.I.; Barrett, C.B.; Buck, L.E.; De Groote, H.; Ferris, S.; Gao, H.O.; McCullough, E.; Miller, D.D.; Outhred, H.; Pell, A.N.; et al. Research principles for developing country food value chains. Science (80) 2011, 332, 1154-1155. [CrossRef] [PubMed]

22. Hawkes, C.; Ruel, M. Value Chains for Nutrition. In Proceedings of the 2020 Conference: Leveraging Agriculture for Improving Nutrition and Health. 2020 Conference Paper \#4, New Delhi, India, 15 February 2011; Volume 4, pp. 1-4.

23. Cucagna, M.E.; Goldsmith, P.D. Value adding in the agri-food value chain: Research article. Int. Food Agribus. Manag. Rev. 2018, 21, 293-316. [CrossRef]

24. Fanzo, J.C.; Downs, S.; Marshall, Q.E.; de Pee, S.; Bloem, M.W. Value Chain Focus on Food and Nutrition Security. In Nutrition and Health in a Developing World, 3rd ed.; de Pee, S., Taren, D., Bloem, M., Eds.; Humana Press: Cham, Switzerland; Totowa, NJ, USA, 2017; pp. 753-770. ISBN 9783319437378.

25. IBR. Analysis Canadian Dairy Farmers: Not Crying Over Spilt Milk. Available online: https: //iveybusinessreview.ca/5738/canadian-dairy-farmers-crying-spilt-milk/ (accessed on 24 May 2020).

26. Bolkvadze, B. Investment Strategy of Georgia as a Country of Transition Economy: Trends, Problems, Prospects. Eur. J. Mark. Econ. 2018, 1, 19. [CrossRef]

27. Mohan, S. Institutional Change in Value Chains: Evidence from Tea in Nepal. World Dev. 2016, 78, 52-65. [CrossRef]

28. FAO. Georgian Milk Producers Learn from Italy and the United States. Available online: http://www.fao.org/ europe/news/detail-news/en/c/1100229/ (accessed on 20 April 2020).

29. Wood, A. Value chains: An economist's perspective. IDS Bull. 2001, 32, 41-45. [CrossRef]

30. Schmitt, E.; Barjolle, D.; Tanquerey-Cado, A.; Brunori, G. Sustainability comparison of a local and a global milk value chains in Switzerland. Bio-based Appl. Econ. 2016, 5, 175-198. [CrossRef]

31. Binder, C.; Schmid, A.; Steinberger, J.K. Sustainability solution space of the Swiss milk value added chain. Ecol. Econ. 2012, 210-220. [CrossRef]

32. Civil Development Agency. Multi-Ethnic Society in Georgia; Civil Development Agency: Rustavi, Georgia, 2011.

33. Kvemo Kartli Region. Available online: http://elibrary.bsu.az/yenii/ebookspdf/uhgkT5jc.pdf (accessed on 15 April 2020).

34. Swiss Agency for Development and Cooperation. Meat and Cheese are Kvemo Kartli's Future; Swiss Agency for Development and Cooperation SDC, Commonwealth of Independent States: Bern, Swiss, 2013.

35. Shukla, S. VARIABLES, Hypotheses and Stages. 2018. Available online: https://www.researchgate. net/publication/325127119_VARIABLES_HYPOTHESES_AND_STAGES_OF_RESEARCH_1 (accessed on 20 April 2020).

36. Rubin, H.J.; Rubin, I.S. Qualitative Interviewing: The Art of Hearing Data; SAGE Publications, Inc: Newbury Park, CA, USA, 2011; ISBN 1412978378.

37. Mayring, P. Qualitative Inhaltsanalyse: Grundlagen und Techniken; Beltz Verlag: Weinheim, Germany; Basel, Switzerland, 2015; ISBN 9783407293930.

38. Edwards, R.; Holland, J. What is Qualitative Interviewing? Bloomsbury Academic: London, UK, 2013; ISBN 9781780938523. 
39. Libakova, N.M.; Sertakova, E.A. The method of expert interview as an effective research procedure of studying the indigenous peoples of the north. J. Sib. Fed. Univ. Humanit. Soc. Sci. 2015, 1, 114-129. [CrossRef]

40. Creswell, J.W. 30 Essential Skills for the Qualitative Researcher; SAGE Publications, Inc.: Newbury Park, CA, USA, 2015.

41. Eriksson, P.; Kovalainen, A. Qualitative Methods in Business Research: A Practical Guide to Social Research; SAGE Publications, Inc.: Newbury Park, CA, USA, 2015; ISBN 1446273393.

42. Cassell, C.; Cunliffe, A.L.; Grandy, G. The SAGE Handbook of Qualitative Business and Management Research Methods; SAGE Publications, Inc.: Newbury Park, CA, USA, 2018; ISBN 9781526429261.

43. Rädiker, S.; Kuckartz, U. Analyse Qualitativer Daten Mit MAXQDA; Springer: Berlin, Germany, 2019; ISBN 9783658220945.

44. Brennan, R.L.; Prediger, D.J. Coefficient kappa: Some uses, misuses, and alternatives. Educ. Psychol. Meas. 1981, 41, 687-699. [CrossRef]

45. Shaburishvili, S. Social Changes and Economic Development in Georgia. 2017. Available online: https://www. researchgate.net/publication/318883168_Social_changes_and_economic_development_in_Georgia (accessed on 20 April 2020).

46. Zubiashvili, T.; Silagadze, L. Some aspects of the Georgian economy at the contemporary stage. Ecoforum 2016, 5, 1-5.

47. ISET Policy Institute. Safety and Quality Investment in Livestock: Georgian Dairy Market System Analysis and Mapping; ISET Policy Institute: Tbilisi, Georgia, 2019.

48. National Statistics Office of Georgia. Geostat Agriculture of Georgia 20201 Quarter, Preliminary Data on Animal Husbandry; National Statistics Office of Georgia: Tbilisi, Georgia, 2020.

49. Mayfield, L.E.; Bennett, R.M.; Tranter, R.B.; Wooldridge, M.J. Consumption of welfare-friendly food products in Great Britain, Italy and Sweden, and how it may be influenced by consumer attitudes to, and behaviour towards, animal welfare attributes. Int. J. Food Agric. 2007, 15, 16.

50. Napolitano, F.; Girolami, A.; Braghieri, A. Consumer liking and willingness to pay for high welfare animal-based products. Trends Food Sci. Technol. 2010, 21, 537-543. [CrossRef]

51. Mounier, L.; Veissier, I. Proceedings of the 6th International Conference on the Assessment of Animal Welfare at the Farm and Group Level; Wageningen Academic Publishers: Wageningen, The Netherlands, 2014; ISBN 978-90-8686-247-4.

52. Rödiger, M.; Janssen, M.; Hamm, U. Multi-Level Animal Welfare Labels Reflect Consumer Preferences: Insights from a Systematic Review; Wageningen Academic Publishers: Ede, The Netherlands, 2017; ISBN 9789086868629.

53. Resolution N 29, Antimicrobial Resistance for 2017-2020 on the Approval of the National Strategy; Government of Georgia: Tbilisi, Georgia, 2017; p. 7. Available online: https://www.ncdc.ge/Handlers/GetFile.ashx?ID= cfaca9b4-17f5-417b-bdad-a37f20209920 (accessed on 20 April 2020).

54. Europe Foundation. Food Safety Regulation in Georgia: Assessment of Government's Reform Efforts in 2016; Europe Foundation: Tbilisi, Georgia, 2016.

55. Ingvartsen, K.L. Feeding- and management-related diseases in the transition cow: Physiological adaptations around calving and strategies to reduce feeding-related diseases. Anim. Feed Sci. Technol. 2006, 126, 175-213. [CrossRef]

56. Oliver, S.P.; Murinda, S.E.; Jayarao, B.M. Impact of antibiotic use in adult dairy cows on antimicrobial resistance of veterinary and human pathogens: A comprehensive review. Foodborne Pathog. Dis. 2011, 8, 337-355. [CrossRef] [PubMed]

57. FAO. Atlas of Origin Linked Food Products in Georgia; FAO: Rome, Italy, 2019.

58. Muehlfried, F. Sharing the same blood-Culture and cuisine in the Republic of Georgia. Anthropol. Food 2008, S3. [CrossRef]

59. FAO. An Overview of Legal and Institutional Frameworks and Opportunities, Challenges and Recommendations for Geographical Indication Products in; FAO: Rome, Italy, 2018.

60. Ministry Of Environmental Protection and Agriculture Of Georgia. EU -Funded Project "Establishing Efficient Protection and Control System of Geographical Indications (GIs) in Georgia". Available online: https://mepa.gov.ge/En/News/Details/11737 (accessed on 16 April 2020).

61. FAO-EBRD. Support to Sustainable Value Chains through the Development of Geographical Indications in the Dairy Sector; European Bank for Reconstruction and Devlopment: London, UK, 2016. 
62. Slow Food USA. Slow Food Costal Georgia. Available online: https://www.slowfoodcoastalga.org/ (accessed on 5 April 2020).

63. TEEB. TEEB for Agriculture \& Food: An Interim Report; TEEB: Geneva, Switzerland, 2015.

64. Ministry of Environment and Natural Resources Protection of Georgia. Fifth National Report to the Convention on Biological Diversity; Ministry of Environment and Natural Resources Protection of Georgia: Tbilisi, Georgia, 2014; pp. 1-221. [CrossRef]

65. Withanachchi, S.S.; Kunchulia, I.; Ghambashidze, G.; Al Sidawi, R.; Urushadze, T.; Ploeger, A. Farmers' perception of water quality and risks in the Mashavera River Basin, Georgia: Analyzing the vulnerability of the social-ecological system through community perceptions. Sustainability 2018, 10, 3062. [CrossRef]

66. Korakhashvili, A.; Jeiranashvili, G. Food safety hazards in Georgian Tushuri Guda cheese. Ann. Agrar. Sci. 2016, 14, 212-216. [CrossRef]

67. Karanja, G.M.; Kiruiro, E.M. Biogas production. Statistics 2003, 107-208. Available online: http://www.kalro. org/fileadmin/publications/tech_notes/tecNote10.pdf (accessed on 16 April 2020).

68. Georgia Department of Agriculture. Georgia's Dairy Industry; Georgia Department of Agriculture: Tbilisi, Georgia, 2014.

69. UN Resolution der Generalversammlung, Resolution der Generalversammlung, verabschiedet am 25. September 2015. 2015. Available online: https://www.un.org/Depts/german/gv-70/band1/ar70001.pdf (accessed on 5 April 2020).

70. FAO. Transforming Food and Agriculture to Achieve the SDGs; FAO: Rome, Italy, 2018; ISBN 9789251306260.

71. UN. First Voluntary National Review On Implementation Of The Sustainable Development Goals; UN: Tbilisi, Georgia, 2016.

72. CARD. Business Case Study Dairy Sector in Georgia; Center for Agribusiness and Rural Development: Tbilisi, Georgia, 2018.

73. Europe Foundation. Food Safety Regulation in Georgia: Assessment of Government's Reform Efforts in 2017; Europe Foundation: Tbilisi, Georgia, 2017.

74. Schubert, R.; Ohndort, M.; Rohling, M. Umweltökonomie Kapitel III: Internalisierung Externer Effekte; Eidgenössische Technische Hochschule Zürich (ETH): Zürich, Switzerland, 2012.

75. Sauer, D. Die Internalisierung Externer Effekte Eine kritische Analyse des Kyoto-Protokolls; GRIN Verlag: Munich, Germany, 2008; ISBN 9783640412167.

76. Willett, W.; Rockström, J.; Loken, B.; Springmann, M.; Lang, T.; Vermeulen, S.; Jonell, M. Food in the Anthropocene: The EAT-Lancet Commission on healthy diets from sustainable food systems. Lancet 2019, 393, 447-492. [CrossRef]

77. Nuffield Council on Bioethics (Great Britain). Public Health: Ethical Issues; Nuffield Council on Bioethics: London, UK, 2007; ISBN 9781904384175.

78. Tilman, D.; Clark, M. Global diets link environmental sustainability and human health. Nature 2014. [CrossRef] [PubMed]

79. Springmann, M.; Godfray, H.C.J.; Rayner, M.; Scarborough, P. Analysis and valuation of the health and climate change cobenefits of dietary change. Proc. Natl. Acad. Sci. USA 2016, 1-6. [CrossRef] [PubMed]

80. Tilman, D.; Clark, M.; Williams, D.R.; Kimmel, K.; Polasky, S.; Packer, C. Future threats to biodiversity and pathways to their prevention. Nature 2017, 546, 73-81. [CrossRef] [PubMed]

81. Smith, J.; Sones, K.; Grace, D.; Macmillan, S.; Tarawali, S.; Herrero, M. Beyond milk, meat, and eggs: Livestock' s role in food and nutrition security. Anim. Front. 2012, 3, 6-13. [CrossRef]

82. Herrero, M.; Havlík, P.; Valin, H.; Notenbaert, A.; Ru, M.C.; Thornton, P.K. Biomass use, production, feed efficiencies, and greenhouse gas emissions from global livestock systems. Proc. Natl. Acad. Sci. USA 2013, 110, 1-6. [CrossRef]

83. Griggs, D.J.; Nilsson, M.; Stevance, A.; McCollum, D. A guide to SDG interactions: From science to implementation. Int. Counc. Sci. Paris 2017. Available online: https://www.sei.org/publications/a-guide-tosdg-interactions-from-science-to-implementation/ (accessed on 16 April 2020).

(C) 2020 by the authors. Licensee MDPI, Basel, Switzerland. This article is an open access article distributed under the terms and conditions of the Creative Commons Attribution (CC BY) license (http://creativecommons.org/licenses/by/4.0/). 